\title{
Modeling, simulation and parametric optimization of wire EDM process using response surface methodology coupled with grey-Taguchi technique
}

\author{
Saurav Datta ${ }^{1}$, Siba Sankar Mahapatra ${ }^{2}$ \\ ${ }^{1 *, 2}$ Department of Mechanical Engineering, National Institute of Technology, NIT Rourkela-769008, Orissa, INDIA \\ *Corresponding Author: e-mail: sdatta@nitrkl.ac.in/ sdattaju@gmail.com, Tel +91-661-246-2524/ Extension (2500)
}

\begin{abstract}
In the present work, quadratic mathematical models have been derived to represent the process behavior of wire electrical discharge machining (WEDM) operation. Experiments have been conducted with six process parameters: discharge current, pulse duration, pulse frequency, wire speed, wire tension and dielectric flow rate; to be varied in three different levels. Data related to the process responses viz. material removal rate (MRR), roughness value of the worked surface (a measure of surface finish, SF) and kerf have been measured for each of the experimental runs; which correspond to randomly chosen different combinations of factor setting. These data have been utilized to fit a quadratic mathematical model (Response Surface Model) for each of the responses, which can be represented as a function of the aforesaid six process parameters. Predicted data have been utilized for identification of the parametric influence in the form of graphical representation for showing influence of the parameters on selected responses. Predicted data given by the models (as per Taguchi's $\mathrm{L}_{27}(3 * 6)$ Orthogonal Array (OA) design) have been used in search of an optimal parametric combination to achieve desired yield of the process: maximum MRR, good surface finish (minimum roughness value) and dimensional accuracy of the product. Grey relational analysis has been adopted to convert this multi-objective criterion into an equivalent single objective function; overall grey relational grade, which has been optimized (maximized) by using Taguchi technique. Optimal setting has been verified through confirmatory test; showed good agreement to the predicted value. This indicates utility of the grey-Taguchi technique as multi-objective optimizer in the field of wire EDM.
\end{abstract}

Keywords: Wire EDM; MRR; response surface methodology; Orthogonal Array (OA)

\section{Introduction}

WEDM is a thermo-electrical process in which material is eroded from the work piece by a series of discrete sparks between the work piece and the wire electrode (tool) separated by a thin film of dielectric fluid (deionized water) which is continuously fed to the machining zone to flush away the eroded particles. The movement of wire is controlled numerically to achieve the desired three-dimensional shape and accuracy of the work piece. The schematic diagram of WEDM is shown in Fig.1 along with dielectric flow, power supply, working table and other control devices.

It is evident from Fig. 1 that it is absolutely essential to hold the wire in a designed position against the object because the wire repeats complex oscillations due to electro-discharge between the wire and work piece. Normally, the wire is held by a pin guide at the upper and lower parts of the work piece. In most cases, the wire will be discarded once used. However, there are problematic points that should be fully considered in order to enhance working accuracy. According to Trezise (1982), the fundamental limits on machining accuracy are dimensional consistency of the wire and the positional accuracy of the worktable. Most of the uncertainties arise because the working region is an unsupported section of the wire, remote from the guides. The detailed section of the working region of the wire electrode is shown in Fig. 2.

Rajurkar and Wang (1993) analyzed the wire rupture phenomena with a thermal model. An extensive experimental investigation has been carried out to determine the variation of machining performance outputs viz., MRR and SF with machining parameters in the study. Tarng et al. (1995) used a neural network system to determine settings of pulse duration, pulse interval, peak current, open circuit voltage, servo reference voltage, electric capacitance, and table speed for the estimation of cutting speed and surface 
finish. Scott et al. (1991) used a factorial design method to determine the optimal combination of control parameters in WEDM, the measures of machining performance being the metal removal rate and the surface finish. Based on the analysis of variance, it was found that discharge current, pulse duration and pulse frequency are significant control factors for both the metal removal rate and surface roughness. Lok and Lee (1997) compared the machining performance in terms of MRR and surface finish through observations obtained by processing of two advanced ceramics under different cutting conditions using WEDM. Huang et al. (1999) investigated experimentally the effect of machining parameters on the gap width, the surface roughness, and the depth of white layer on the machined work piece surface. Rozenek et al. (2001) used a metal matrix composite as work piece material and investigated the variation of machining feed rate and surface roughness with machining parameters. Tosun and Cogun (2003) investigated the effect of machining parameters on wire wear ratio based on the weight loss of wire in WEDM. Tosun et al. (2003) introduced a statistical approach to determine the optimal machining parameters for minimum size of wire craters in WEDM. Mahapatra and Patnaik (2007) applied Taguchi method and Genetic Algorithm to obtain an optimal parametric combination to achieve desired quality of the machined product. It was found that; it may so happen, the optimal result predicted by GA cannot be achieved in reality; due to nonexistence of the optimal parameter combination in the machine. So, in reality a compromise has to be made to select the next possible factor combination; very close to the optimal. Taguchi method is comparatively advantageous in that context. It selects levels of parameters which are included in the capacity of parameter variation of the machine; and the optimal setting it offers, can be inserted to the machine. But the drawback of Taguchi technique is that it cannot solve multiobjective optimization problem.

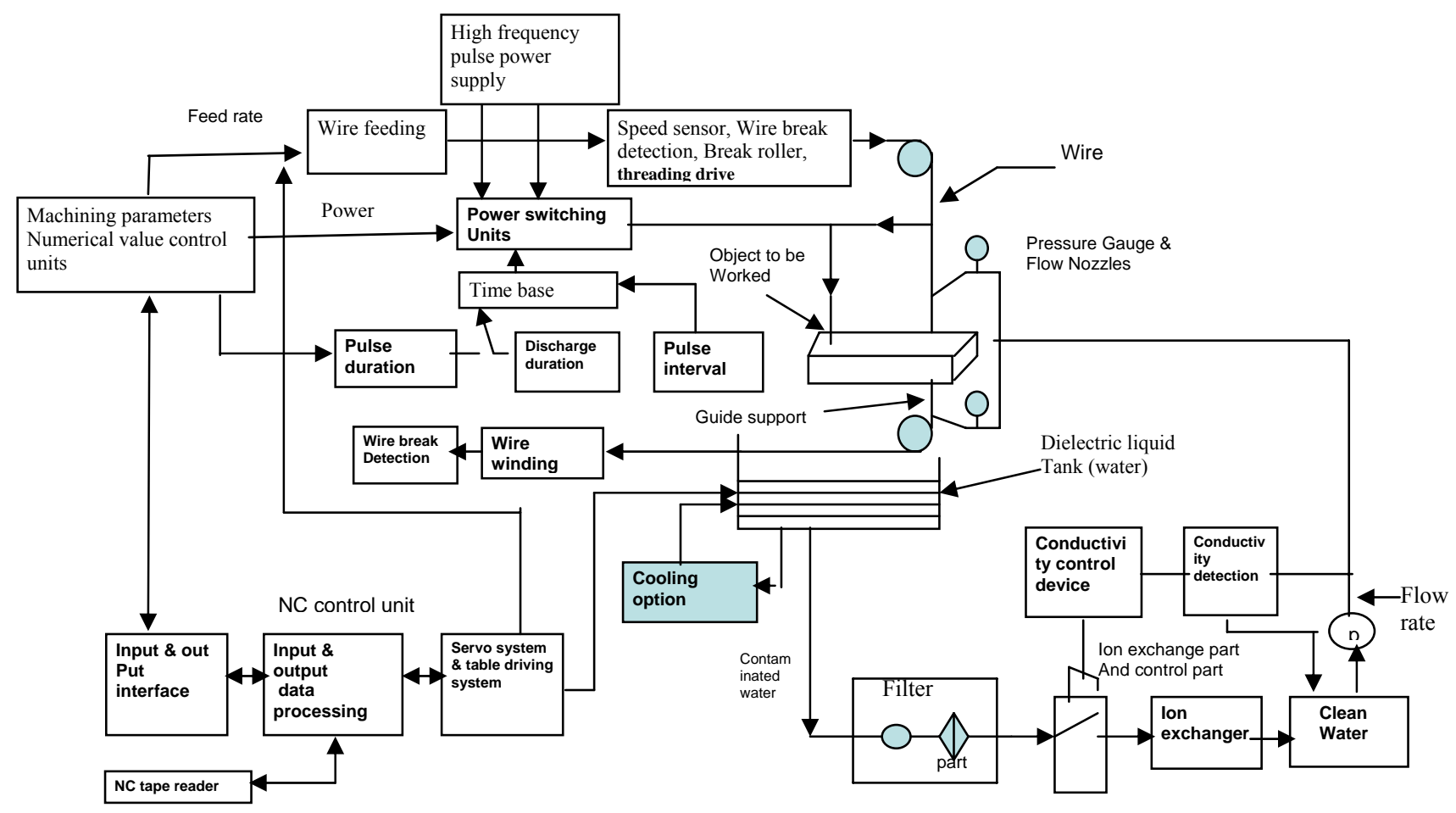

Figure 1. Schematic diagram of WEDM (Mahapatra and Patnaik, 2007)

The most important performance measures in WEDM are metal removal rate, surface finish and cutting width (kerf). They depend on machining parameters like discharge current, pulse duration, pulse frequency, wire speed, wire tension and dielectric flow rate. Among other performance measures, the kerf, which determines the dimensional accuracy of the finishing part, is of extreme importance. The internal corner radius to be produced in WEDM operations is also limited by the kerf. The gap between wire and work piece usually ranges from 0.025 to $0.075 \mathrm{~mm}$ and is constantly maintained by a computer controlled positioning system. In WEDM operations, material removal rate determine the economics of machining and rate of production where as kerf denotes degree of precision.

In setting the machining parameters, particularly in rough cutting operation, the goal is threefold - the maximization of MRR, maximization of SF and minimization of kerf. Generally, the machine tool builder provides machining parameter table to be used for setting machining parameter. This process relies heavily on the experience of the operators. In practice, it is very difficult to utilize the optimal functions of a machine owing to there being too many adjustable machining parameters. With a view to alleviate this difficulty, a simple but reliable method based on statistically designed experiments is suggested for investigating the 
effects of various process parameters on MRR, SF and kerf and determines optimal process settings. In the present work, data have been collected from few experimental runs with randomly chosen factor combinations. A quadratic model has been fitted for identification of the process to establish approximate interrelation among various process parameters as well as response variables. These mathematical models have been utilized to generate data as per Taguchi design. Finally, grey-based Taguchi technique has been adopted to evaluate the optimal process environment.

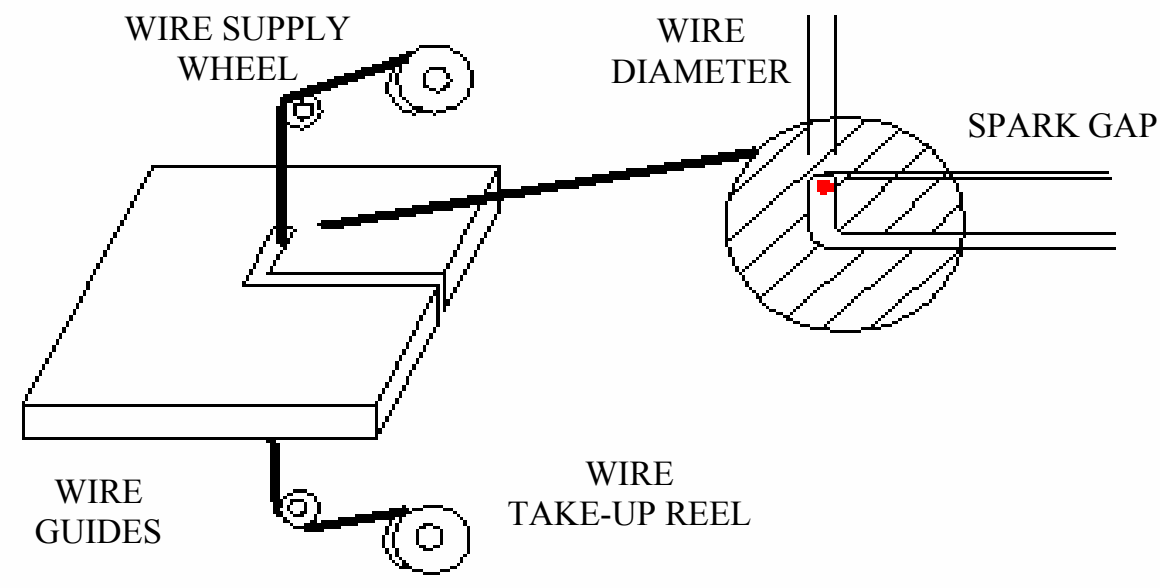

Figure 2. Detail of WEDM cutting gap (Mahapatra and Patnaik, 2007)

\section{Experimentation and Data Collection}

The experiments have been performed on ROBOFIL 100 high precision 5 axis CNC WEDM, which is manufactured by Charmilles Technologies Corporation. The basic parts of the WEDM machine consists of a wire, a worktable, a servo control system, a power supply and dielectric supply system. The ROBOFIL 100 allows the operator to choose input parameters according to the material and height of the work piece and tool material from a manual provided by the WEDM manufacturer. The ROBOFIL 100 WED machine has several special features. The pulse power supply uses a transistor controlled RC circuit. The discharge energy is determined by the value of the capacitor that is parallel to the machining gap. The experimental set-up for the data acquisition of the sparking frequency and machine table speed is illustrated in Fig. 3.

The input and fixed parameters used in the present study are also listed in Table 1 . These have been chosen through review of literature, experience, and some preliminary investigations. Different settings of discharge current, pulse duration, pulse frequency, wire speeds, wire tension, and dielectric flow rate used in the experiments are shown in Table 2.

Table 1. Parameters of the setting

\begin{tabular}{|c|c|c|c|}
\hline \multicolumn{2}{|l|}{ Control Factors } & \multicolumn{2}{|c|}{ Fixed parameters } \\
\hline Discharge Current & $X_{1}$ & Wire & $\begin{array}{l}\text { Zinc coated copper wire, } \\
\text { Stratified, copper, } \\
\text { diameter } 0.25 \mathrm{~mm}\end{array}$ \\
\hline Pulse Duration & $X_{2}$ & Shape & Rectangular product \\
\hline Pulse Frequency & $X_{3}$ & $\begin{array}{l}\text { Location of work } \\
\text { piece on working } \\
\text { table }\end{array}$ & At the center of the table \\
\hline Wire Speed & $X_{4}$ & Angle of cut & Vertical \\
\hline Wire Tension & $X_{5}$ & $\begin{array}{l}\text { Dimension of work } \\
\text { piece }\end{array}$ & $\begin{array}{l}\text { Thickness }=10 \mathrm{~mm} \\
\text { Height }=25 \mathrm{~mm}\end{array}$ \\
\hline Dielectric Flow Rate & $X_{6}$ & Stability & Servo control \\
\hline
\end{tabular}

Each time an experiment has been performed, a particular set of input parameters has been chosen and the work piece, a block of $\mathrm{D} 2$ tool steel $(1.5 \% \mathrm{C}, 12 \% \mathrm{Cr}, 0.6 \% \mathrm{~V}, 1 \% \mathrm{Mo}, 0.6 \% \mathrm{Si}, 0.6 \% \mathrm{Mn}$ and balance $\mathrm{Fe})$ with $200 \mathrm{~mm} \times 25 \mathrm{~mm} \times 10 \mathrm{~mm}$ size, has been cut $100 \mathrm{~mm}$ length with $10 \mathrm{~mm}$ depth along the longer length. A $0.25 \mathrm{~mm}$ diameter stratified wire (Zinc coated copper wire) with vertical configuration has been used and discarded once used. High MRR in WEDM without wire breakage can be attained by the use of zinc coated copper wire because evaporation of zinc causes cooling at the interface of work piece and wire and a coating of zinc oxide on the surface of wire helps to prevent short-circuits (Sho et al., 1989). 


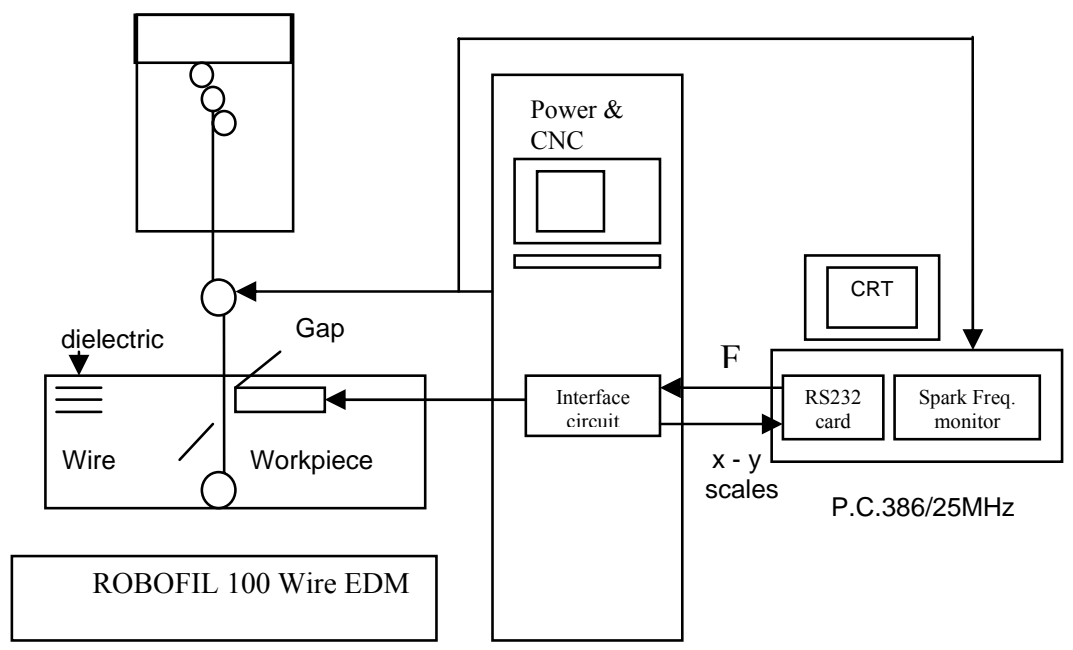

Figure 3. Experimental set-up of Robofil100 WEDM (Mahapatra and Patnaik, 2007)

Table 2. Control factors and their limits (domain of experiments)

\begin{tabular}{|l|c|c|c|c|}
\hline \multicolumn{5}{|c|}{ Level } \\
\hline \multicolumn{1}{|c|}{ Control Factor } & 1 & 2 & 3 & Unit \\
\hline Discharge Current & 16.00 & 24.00 & 32.00 & $\mathrm{amp}$ \\
\hline Pulse Duration & 3.20 & 6.40 & 12.80 & $\mu \mathrm{sec}$ \\
\hline Pulse Frequency & 40.00 & 50.00 & 60.00 & $\mathrm{KHz}$ \\
\hline Wire Speed & 7.60 & 8.60 & 9.20 & $\mathrm{~m} / \mathrm{min}$ \\
\hline Wire Tension & 1000.00 & 1100.00 & 1200.00 & $\mathrm{~g}$ \\
\hline Dielectric Flow Rate & 1.20 & 1.30 & 1.40 & bars \\
\hline
\end{tabular}

The most important performance measures in WEDM are metal removal rate, work piece surface finish and cutting width. The surface finish value (in $\mu \mathrm{m}$ ) has been obtained by measuring the mean absolute deviation, $R_{a}$ (surface roughness) from the average surface level using a type C3A Mahr Perthen Perthometer (stylus radius of $5 \mu \mathrm{m}$ ). The kerf has been measured using the Mitutoyo tools makers' microscope (x100), which can be expressed as sum of the wire diameter and twice of wire-work piece gap. The kerf value is the average of five measurements made from the work piece with $20 \mathrm{~mm}$ increments along the cut length. MRR is calculated as,

$M R R=k \cdot t \cdot v_{c} \cdot \rho$

Here, $\mathrm{k}$ is the kerf, $\mathrm{t}$ is the thickness of work piece $(10 \mathrm{~mm}), \mathrm{v}_{\mathrm{c}}$ is cutting speed and $\rho$ is the density of the work piece material $(7.8$ $\left.\mathrm{g} / \mathrm{cm}^{3}\right)$.

\section{Table Figures and Equations}

The response function representing each of the six responses can be expressed as follow:

$Y=f\left(X_{1}, X_{2}, X_{3}, X_{4}, X_{5}, X_{6}\right)$

Here $Y=$ Response and $\left.X_{i}\right|_{i=1,2,3,4,5,6}$ are the factors.

The second order response surface model for the six selected parameters is given by equation (3):

$Y=\beta_{0}+\sum_{i=1}^{6} \beta_{i} X_{i}+\sum_{i=1}^{6} \beta_{i i} X_{i}^{2}+\sum_{i=1}^{6} \beta_{i j} X_{i} X_{j}$

The above second order response surface model could be expressed as follows: 


$$
\begin{aligned}
Y= & \beta_{0}+\beta_{1} X_{1}+\beta_{2} X_{2}+\beta_{3} X_{3}+\beta_{4} X_{4}+\beta_{5} X_{5}+\beta_{6} X_{6} \\
& +\beta_{11} X_{1}^{2}+\beta_{22} X_{2}^{2}+\beta_{33} X_{3}^{2}+\beta_{44} X_{4}^{2}+\beta_{55} X_{5}^{2}+\beta_{66} X_{6}^{2}+\beta_{12} X_{1} X_{2}+\beta_{16} X_{1} X_{6}
\end{aligned}
$$

Here $\beta_{0}$ is free term of the regression equation, the coefficients of quadratic terms are $\beta_{11}, \beta_{22}, \beta_{33}, \beta_{44}, \beta_{55}, \beta_{66}$ and the coefficients $\beta_{12}, \beta_{16}$ are interaction terms.

Based on information available from the literature; the interactive terms of the factors $X_{1} * X_{2}$ and $X_{1} * X_{6}$ have been highlighted in the proposed model. Interaction effect of other parameters has been assumed negligible; therefore, the corresponding interactive terms have been omitted from the model.

The above mathematical model (equation 3) can be simplified into a linear regression model as follow:

$$
\begin{aligned}
Y= & a_{0}+a_{1} X_{1}^{\prime}+a_{2} X_{2}^{\prime}+a_{3} X_{3}^{\prime}+a_{4} X_{4}^{\prime}+a_{5} X_{5}^{\prime}+a_{6} X_{6}^{\prime} \\
& +a_{7} X_{7}^{\prime}+a_{8} X_{8}^{\prime}+a_{9} X_{9}^{\prime}+a_{10} X_{10}^{\prime}+a_{11} X_{11}^{\prime}+a_{12} X_{12}^{\prime}+a_{13} X_{13}^{\prime}+a_{14} X_{14}^{\prime}
\end{aligned}
$$

Here,

$$
\begin{aligned}
& a_{0}=\beta_{0}, a_{1}=\beta_{1}, a_{2}=\beta_{2}, a_{3}=\beta_{3}, a_{4}=\beta_{4}, a_{5}=\beta_{5}, a_{6}=\beta_{6}, a_{7}=\beta_{11}, a_{8}=\beta_{22}, a_{9}=\beta_{33}, \\
& a_{10}=\beta_{44}, a_{11}=\beta_{55}, a_{12}=\beta_{66}, a_{13}=\beta_{12}, a_{14}=\beta_{16} \\
& \text { and } X_{1}^{\prime}=X_{1}, X_{2}^{\prime}=X_{2}, X_{3}^{\prime}=X_{3}, X_{4}^{\prime}=X_{4}, X_{5}^{\prime}=X_{5}, X_{6}^{\prime}=X_{6}, X_{7}^{\prime}=X_{1}^{2}, \\
& \quad X_{8}^{\prime}=X_{2}^{2}, X_{9}^{\prime}=X_{3}^{2}, X_{10}^{\prime}=X_{4}^{2}, X_{11}^{\prime}=X_{5}^{2}, X_{12}^{\prime}=X_{6}^{2}, X_{13}^{\prime}=X_{1} X_{2}, X_{14}^{\prime}=X_{1} X_{6}
\end{aligned}
$$

The coefficients of the linear regression model (equation 5) have been evaluated by statistical Software Package MINITAB 14. The level of significance of the factor coefficients have been checked by Analysis of Variance (ANOVA) technique at $95 \%$ confidence level. The final reduced models for MRR, SF and kerf are given below in equations (6) to (8); and represented graphically in the Appendix (Fig. a to $\mathrm{r}$ ). The trends have been found consistent to interpret the correlation among process parameters as well as process responses physically. Those trends have been tabulated in Table 11 of Appendix.

$$
\begin{aligned}
& M R R=0.0253+0.0748 X_{1}+0.129 X_{2}-0.0072 X_{3}+0.0003 X_{4}-0.0108 X_{5}-0.0395 X_{6} \\
& \quad-0.0147 X_{1}^{2}-0.0252 X_{2}^{2}+0.00233 X_{3}^{2}-0.00073 X_{4}^{2}+0.00221 X_{5}^{2}+0.00599 X_{6}^{2} \\
& \quad-0.00905 X_{1} X_{2}+0.00588 X_{1} X_{6} \\
& R_{a}=3.37+0.0761 X_{1}+0.356 X_{2}-0.0194 X_{3}+0.0456 X_{4}-0.0144 X_{5}-0.0944 X_{6} \\
& \quad-0.0156 X_{1}^{2}-0.0606 X_{2}^{2}+0.0061 X_{3}^{2}-0.0122 X_{4}^{2}+0.0011 X_{5}^{2}+0.0061 X_{6}^{2} \\
& \quad-0.0067 X_{1} X_{2}+0.0242 X_{1} X_{6} \\
& \text { Kerf }=0.095+0.0863 X_{1}+0.197 X_{2}-0.0082 X_{3}+0.0067 X_{4}-0.0225 X_{5}-0.0919 X_{6} \\
& \quad-0.0224 X_{1}^{2}-0.0386 X_{2}^{2}+0.0028 X_{3}^{2}-0.0024 X_{4}^{2}+0.0053 X_{5}^{2}+0.0096 X_{6}^{2} \\
& \quad-0.0142 X_{1} X_{2}+0.0243 X_{1} X_{6}
\end{aligned}
$$

\section{Parametric optimization}

\subsection{Data generation as per Taguchi $L_{27} O A$ design}

The WEDM process consists of three operations, a roughing operation, a finishing operation, and a surface finishing operation. Usually, performance of various types of cutting operations is judged by different measures. In case of finish cutting operation, the surface finish is of primary importance whereas both metal removal rate and surface finish are of primary importance for rough cutting operation. Dimensional accuracy is highly dependent on cutting width. This means that the rough cutting operation is more 
challenging because three goals must be satisfied simultaneously. Therefore, the rough cutting phase is investigated in the present approach considering three performance goals like MRR, SF and kerf. In this study, Taguchi method, a powerful tool for parameter design of the performance characteristics has been used to determine optimal machining parameters for maximization of MRR and minimization of SF and kerf in wire EDM.

Experiments have been carried out using Taguchi's $\mathrm{L}_{27}$ Orthogonal Array (OA) experimental design which consists of 27 combinations of six process parameters. According to the design catalogue (Peace, 1993) prepared by Taguchi, $\mathrm{L}_{27}$ Orthogonal Array design of experiment has been found suitable in the present work. It considers four process parameters (without interaction) to be varied in three discrete levels. Based on Taguchi's $\mathrm{L}_{27}$ Orthogonal Array design (Table 3), the predicted data provided by the mathematical models can be transformed into a signal-to-noise $(\mathrm{S} / \mathrm{N})$ ratio; based on three criteria. The characteristic that higher value represents better machining performance, such as MRR, 'higher-the-better, HB; and inversely, the characteristic that lower value represents better machining performance, such as surface roughness, kerf is called 'lower-the-better', LB. Therefore, HB for the MRR, LB for the SF and kerf have been selected for obtaining optimum machining performance characteristics. The loss function (L) for objective of HB and LB is defined as follows:

$$
\begin{aligned}
& L_{H B}=\frac{1}{n} \sum_{i=1}^{n} \frac{1}{y_{M R R}^{2}} \\
& L_{L B}=\frac{1}{n} \sum_{i=1}^{n} y_{S F}^{2} \\
& L_{L B}=\frac{1}{n} \sum_{i=1}^{n} y_{\mathrm{ker} f}^{2}
\end{aligned}
$$

Here $y_{M R R}, y_{S F}$ and $y_{\text {ker } f}$ represent response for metal removal rate, surface finish and cutting width respectively and $\mathrm{n}$ denotes the number of experiments.

Table 3. Taguchi's $\mathrm{L}_{27} \mathrm{OA}$ design

\begin{tabular}{|c|c|c|c|c|c|c|}
\hline Ex. No. & $X_{1}$ & $X_{2}$ & $X_{3}$ & $X_{4}$ & $X_{5}$ & $X_{6}$ \\
\hline 1 & 1 & 1 & 1 & 1 & 1 & 1 \\
\hline 2 & 1 & 1 & 1 & 1 & 2 & 2 \\
\hline 3 & 1 & 1 & 1 & 1 & 3 & 3 \\
\hline 4 & 1 & 2 & 2 & 2 & 1 & 1 \\
\hline 5 & 1 & 2 & 2 & 2 & 2 & 2 \\
\hline 6 & 1 & 2 & 2 & 2 & 3 & 3 \\
\hline 7 & 1 & 3 & 3 & 3 & 1 & 1 \\
\hline 8 & 1 & 3 & 3 & 3 & 2 & 2 \\
\hline 9 & 1 & 3 & 3 & 3 & 3 & 3 \\
\hline 10 & 2 & 1 & 2 & 3 & 1 & 2 \\
\hline 11 & 2 & 1 & 2 & 3 & 2 & 3 \\
\hline 12 & 2 & 1 & 2 & 3 & 3 & 1 \\
\hline 13 & 2 & 2 & 3 & 1 & 1 & 2 \\
\hline 14 & 2 & 2 & 3 & 1 & 2 & 3 \\
\hline 15 & 2 & 2 & 3 & 1 & 3 & 1 \\
\hline 16 & 2 & 3 & 1 & 2 & 1 & 2 \\
\hline 17 & 2 & 3 & 1 & 2 & 2 & 3 \\
\hline 18 & 2 & 3 & 1 & 2 & 3 & 1 \\
\hline 19 & 3 & 1 & 3 & 2 & 1 & 3 \\
\hline 20 & 3 & 1 & 3 & 2 & 2 & 1 \\
\hline 21 & 3 & 1 & 3 & 2 & 3 & 2 \\
\hline 22 & 3 & 2 & 1 & 3 & 1 & 3 \\
\hline 23 & 3 & 2 & 1 & 3 & 2 & 1 \\
\hline 24 & 3 & 2 & 1 & 3 & 3 & 2 \\
\hline 25 & 3 & 3 & 2 & 1 & 1 & 3 \\
\hline 26 & 3 & 3 & 2 & 1 & 2 & 1 \\
\hline 27 & 3 & 3 & 2 & 1 & 3 & 2 \\
\hline
\end{tabular}


The $\mathrm{S} / \mathrm{N}$ ratio can be calculated as a logarithmic transformation of the loss function as shown below.

$\mathrm{S} / \mathrm{N}$ ratio for $\mathrm{MRR}=-10 \log _{10}\left(L_{H B}\right)$

$\mathrm{S} / \mathrm{N}$ ratio for $\mathrm{SF}=-10 \log _{10}\left(L_{L B}\right)$

$\mathrm{S} / \mathrm{N}$ ratio for $\operatorname{kerf}=-10 \log _{10}\left(L_{L B}\right)$

The optimal setting would be the one which could achieve highest $\mathrm{S} / \mathrm{N}$ ratio. However, traditional Taguchi method can optimize a single objective function; it cannot solve multi-objective optimization problem (Datta et al., 2006; Moshat et al., 2010). So, MRR, SF and kerf can be optimized individually by using this Taguchi technique. But it may so happen that, the optimal setting for a response variable cannot ensure other response variables within acceptable limits. So, one should go for such an optimal parameter setting so that all the objectives should fulfill simultaneously; (maximum MRR, minimum SF and minimum kerf). These will be achieved using grey based Taguchi method as discussed below. This method can convert several objective functions into an equivalent single objective function (representative of all desired response characteristics of the product/process), which would be maximized next.

\subsection{Grey relational analysis theory}

In grey relational analysis, experimental data i.e. measured features of quality characteristics are first normalized ranging from zero to one. The process is known as grey relational generation. Next, based on normalized experimental data, grey relational coefficient is calculated to represent the correlation between the desired and actual experimental data. Then overall grey relational grade is determined by averaging the grey relational coefficient corresponding to selected responses. The overall performance characteristic of the multiple response process depends on the calculated grey relational grade. This approach converts a multiple response process optimization problem into a single response optimization situation with the objective function is overall grey relational grade. The optimal parametric combination is then evaluated which would result into highest grey relational grade. The optimal factor setting for maximizing overall grey relational grade can be performed by Taguchi method.

In grey relational generation, the normalized data i.e. surface finish and cutting width, corresponding to lower-the-better (LB) criterion can be expressed as (Datta et al., 2008):

$$
x_{i}(k)=\frac{\max y_{i}(k)-y_{i}(k)}{\max y_{i}(k)-\min y_{i}(k)}
$$

MRR should follow higher-the-better criterion (HB), which can be expressed as:

$$
x_{i}(k)=\frac{y_{i}(k)-\min y_{i}(k)}{\max y_{i}(k)-\min y_{i}(k)}
$$

Here $x_{i}(k)$ is the value after grey relational generation, $\min y_{i}(k)$ is the smallest value of $y_{i}(k)$ for the $k t h$ response, and $\max y_{i}(k)$ is the largest value of $y_{i}(k)$ for the $k$ th response. An ideal sequence is $x_{0}(k)(k=1,2,3, \ldots \ldots ., 27)$ for the responses. The definition of grey relational grade in the course of grey relational analysis is to reveal the degree of relation between the 27 sequences $x_{0}(k)$ and $x_{i}(k),(k=1,2,3, \ldots \ldots, 27)$. The grey relational coefficient $\xi_{i}(k)$ can be calculated as:

$$
\xi_{i}(k)=\frac{\Delta_{\min }+\psi \Delta_{\max }}{\Delta_{0 i}(k)+\psi \Delta_{\max }}
$$

Here $\Delta_{0 i}=\left\|x_{0}(k)-x_{i}(k)\right\|=$ difference of absolute value $x_{0}(k)$ and $x_{i}(k) ; \psi$ is the distinguishing coefficient $0 \leq \psi \leq 1$; $\Delta_{\text {min }}=\forall j^{\min } \in i \forall k^{\min }\left\|x_{0}(k)-x j(k)\right\|=$ the smallest value of $\Delta_{0 i}$; and $\Delta_{\max }=\forall j^{\max } \in i \forall k^{\max }\left\|x_{0}(k)-x j(k)\right\|=$ the largest value of $\Delta_{0 i}$. After averaging the grey relational coefficients, the grey relational grade $\gamma_{i}$ can be computed as:

$\gamma_{i}=\frac{1}{n} \sum_{k=1}^{n} \xi_{i}(k)$

Here $n$ is the number of process responses.

The higher value of grey relational grade corresponds to intense relational degree between the reference sequence $x_{0}(k)$ and the given sequence $x_{i}(k)$. The reference sequence $x_{0}(k)$ represents the best process sequence; therefore, higher grey relational grade means that the corresponding parameter combination is closer to the optimal. The mean response for the grey relational 
grade with its grand mean and the main effect plot of grey relational grade are very important because optimal process condition can be evaluated from this plot.

\subsection{Grey-Taguchi technique for multi-objective optimization}

Generated data (Table 4) have been normalized first (grey relational generation). The normalized data for each of the parameters of process output viz. MRR, $\mathrm{R}_{\mathrm{a}}$, Kerf have been furnished in Table 5. Grey relational coefficients for each performance characteristics have been calculated and furnished in Table 7. This calculation requires the estimation of quality loss $\Delta_{0 i}$ of each response from its best suited value (Table 6). These grey relational coefficients for each response have been accumulated to evaluate overall grey relational grade (Table 8). Equal weight age has been given to all the responses $(0.333)$. The mean response Table for the overall grey relational grade is shown in Table 9. The optimal parameter setting has been evaluated from the Figure 3. The optimal setting comes:

\begin{tabular}{cc}
\hline Parameter & Optimal level \\
\hline$X_{1}$ & 1 \\
$X_{2}$ & 1 \\
$X_{3}$ & 1 \\
$X_{4}$ & 1 \\
$X_{5}$ & 3 \\
$X_{6}$ & 3 \\
\hline
\end{tabular}

The optimal setting has been verified by confirmatory test, showed good agreement with the predicted value. This has been shown in Table 10.

Table 4. Response data

\begin{tabular}{|c|c|c|c|}
\hline Ex. No. & $\begin{array}{c}\text { MRR } \\
(\mathrm{g} / \mathrm{min})\end{array}$ & $\begin{array}{c}\mathrm{R}_{\mathrm{a}} \\
(\mu \mathrm{m})\end{array}$ & $\begin{array}{c}\text { Kerf } \\
(\mathrm{mm})\end{array}$ \\
\hline 1 & 0.2114 & 3.7195 & 0.3516 \\
\hline 2 & 0.2006 & 3.6107 & 0.3291 \\
\hline 3 & 0.1898 & 3.5019 & 0.3066 \\
\hline 4 & 0.3335 & 4.1017 & 0.5471 \\
\hline 5 & 0.3227 & 3.9929 & 0.5246 \\
\hline 6 & 0.3119 & 3.8841 & 0.5021 \\
\hline 7 & 0.4556 & 4.4839 & 0.7426 \\
\hline 8 & 0.4448 & 4.3751 & 0.7201 \\
\hline 9 & 0.4340 & 4.2663 & 0.6976 \\
\hline 10 & 0.2796 & 3.7730 & 0.4404 \\
\hline 11 & 0.2688 & 3.6642 & 0.4179 \\
\hline 12 & 0.2580 & 3.8386 & 0.3954 \\
\hline 13 & 0.4008 & 4.0184 & 0.6158 \\
\hline 14 & 0.3900 & 3.9096 & 0.5933 \\
\hline 15 & 0.3792 & 4.0840 & 0.5708 \\
\hline 16 & 0.5445 & 4.4588 & 0.8359 \\
\hline 17 & 0.5337 & 4.3500 & 0.8134 \\
\hline 18 & 0.5229 & 4.5244 & 0.7909 \\
\hline 19 & 0.3469 & 3.6897 & 0.5091 \\
\hline 20 & 0.3361 & 3.8641 & 0.4866 \\
\hline 21 & 0.3253 & 3.7553 & 0.4641 \\
\hline 22 & 0.4906 & 4.1301 & 0.7292 \\
\hline 23 & 0.4798 & 4.3045 & 0.7067 \\
\hline 24 & 0.4690 & 4.1957 & 0.6842 \\
\hline 25 & 0.6118 & 4.3755 & 0.9046 \\
\hline 26 & 0.6010 & 4.5499 & 0.8821 \\
\hline 27 & 0.5902 & 4.4411 & 0.8596 \\
\hline & & & \\
\hline
\end{tabular}


Table 5. Normalized data (Grey relational generation)

\begin{tabular}{|c|c|c|c|}
\hline Ex. No. & $\begin{array}{c}\text { MRR } \\
(\mathrm{g} / \mathrm{min})\end{array}$ & $\begin{array}{c}\mathrm{R}_{\mathrm{a}} \\
(\mu \mathrm{m})\end{array}$ & $\begin{array}{c}\text { Kerf } \\
(\mathrm{mm})\end{array}$ \\
\hline 1 & 0.0512 & 0.7924 & 0.9247 \\
\hline 2 & 0.0256 & 0.8962 & 0.9624 \\
\hline 3 & 0.0000 & 1.0000 & 1.0000 \\
\hline 4 & 0.3405 & 0.4277 & 0.5978 \\
\hline 5 & 0.3149 & 0.5315 & 0.6355 \\
\hline 6 & 0.2893 & 0.6353 & 0.6731 \\
\hline 7 & 0.6299 & 0.0630 & 0.2709 \\
\hline 8 & 0.6043 & 0.1668 & 0.3085 \\
\hline 9 & 0.5787 & 0.2706 & 0.3462 \\
\hline 10 & 0.2128 & 0.7413 & 0.7763 \\
\hline 11 & 0.1872 & 0.8451 & 0.8139 \\
\hline 12 & 0.1616 & 0.6787 & 0.8515 \\
\hline 13 & 0.5000 & 0.5072 & 0.4829 \\
\hline 14 & 0.4744 & 0.6110 & 0.5206 \\
\hline 15 & 0.4488 & 0.4446 & 0.5582 \\
\hline 16 & 0.8405 & 0.0869 & 0.1149 \\
\hline 17 & 0.8149 & 0.1907 & 0.1525 \\
\hline 18 & 0.7893 & 0.0243 & 0.1901 \\
\hline 19 & 0.3723 & 0.8208 & 0.6614 \\
\hline 20 & 0.3467 & 0.6544 & 0.6990 \\
\hline 21 & 0.3211 & 0.7582 & 0.7366 \\
\hline 22 & 0.7128 & 0.4006 & 0.2933 \\
\hline 23 & 0.6872 & 0.2342 & 0.3309 \\
\hline 24 & 0.6616 & 0.3380 & 0.3686 \\
\hline 25 & 1.0000 & 0.1664 & 0.0000 \\
\hline 26 & 0.9744 & 0.0000 & 0.0376 \\
\hline 27 & 0.9488 & 0.1038 & 0.0753 \\
\hline & & & \\
\hline
\end{tabular}

Table 6. Evaluation of $\Delta_{0 i}$ for each of the responses

\begin{tabular}{|c|c|c|c|}
\hline Ex. No. & $\begin{array}{c}\text { MRR } \\
(\mathrm{g} / \mathrm{min})\end{array}$ & $\begin{array}{c}\mathrm{R}_{\mathrm{a}} \\
(\mu \mathrm{m})\end{array}$ & $\begin{array}{c}\text { Kerf } \\
(\mathrm{mm})\end{array}$ \\
\hline Ideal Sequence & 1 & 1 & 1 \\
\hline 1 & 0.9488 & 0.2076 & 0.0753 \\
\hline 2 & 0.9744 & 0.1038 & 0.0376 \\
\hline 3 & 1.0000 & 0.0000 & 0.0000 \\
\hline 4 & 0.6595 & 0.5723 & 0.4022 \\
\hline 5 & 0.6851 & 0.4685 & 0.3645 \\
\hline 6 & 0.7107 & 0.3647 & 0.3269 \\
\hline 7 & 0.3701 & 0.9370 & 0.7291 \\
\hline 8 & 0.3957 & 0.8332 & 0.6915 \\
\hline 9 & 0.4213 & 0.7294 & 0.6538 \\
\hline 10 & 0.7872 & 0.2587 & 0.2237 \\
\hline 11 & 0.8128 & 0.1549 & 0.1861 \\
\hline 12 & 0.8384 & 0.3213 & 0.1485 \\
\hline 13 & 0.5000 & 0.4928 & 0.5171 \\
\hline 14 & 0.5256 & 0.3890 & 0.4794 \\
\hline 15 & 0.5512 & 0.5554 & 0.4418 \\
\hline 16 & 0.1595 & 0.9131 & 0.8851 \\
\hline 17 & 0.1851 & 0.8093 & 0.8475 \\
\hline 18 & 0.2107 & 0.9757 & 0.8099 \\
\hline 19 & 0.6277 & 0.1792 & 0.3386 \\
\hline
\end{tabular}




\begin{tabular}{|c|c|c|c|}
\hline Ex. No. & $\begin{array}{c}\text { MRR } \\
(\mathrm{g} / \mathrm{min})\end{array}$ & $\begin{array}{c}\mathrm{R}_{\mathrm{a}} \\
(\mu \mathrm{m})\end{array}$ & $\begin{array}{c}\text { Kerf } \\
(\mathrm{mm})\end{array}$ \\
\hline Ideal Sequence & 1 & 1 & 1 \\
\hline 20 & 0.6533 & 0.3456 & 0.3010 \\
\hline 21 & 0.6789 & 0.2418 & 0.2634 \\
\hline 22 & 0.2872 & 0.5994 & 0.7067 \\
\hline 23 & 0.3128 & 0.7658 & 0.6691 \\
\hline 24 & 0.3384 & 0.6620 & 0.6314 \\
\hline 25 & 0.0000 & 0.8336 & 1.0000 \\
\hline 26 & 0.0256 & 1.0000 & 0.9624 \\
\hline 27 & 0.0512 & 0.8962 & 0.9247 \\
\hline
\end{tabular}

Table 7. Grey relational coefficient of each performance characteristics ( $\Psi=0.5$ )

\begin{tabular}{|c|c|c|c|}
\hline Ex. No. & $\begin{array}{c}\text { MRR } \\
\text { (g/min) }\end{array}$ & $\begin{array}{c}\mathrm{R}_{\mathrm{a}} \\
(\mu \mathrm{m})\end{array}$ & $\begin{array}{l}\text { Kerf } \\
(\mathrm{mm})\end{array}$ \\
\hline 1 & 0.3451 & 0.7066 & 0.8691 \\
\hline 2 & 0.3391 & 0.8281 & 0.9301 \\
\hline 3 & 0.3333 & 1.0000 & 1.0000 \\
\hline 4 & 0.4312 & 0.4663 & 0.5542 \\
\hline 5 & 0.4219 & 0.5163 & 0.5784 \\
\hline 6 & 0.4130 & 0.5782 & 0.6047 \\
\hline 7 & 0.5746 & 0.3479 & 0.4068 \\
\hline 8 & 0.5582 & 0.3750 & 0.4196 \\
\hline 9 & 0.5427 & 0.4067 & 0.4334 \\
\hline 10 & 0.3884 & 0.6590 & 0.6909 \\
\hline 11 & 0.3809 & 0.7635 & 0.7288 \\
\hline 12 & 0.3736 & 0.6088 & 0.7710 \\
\hline 13 & 0.5000 & 0.5036 & 0.4916 \\
\hline 14 & 0.4875 & 0.5624 & 0.5105 \\
\hline 15 & 0.4756 & 0.4738 & 0.5309 \\
\hline 16 & 0.7582 & 0.3538 & 0.3610 \\
\hline 17 & 0.7298 & 0.3819 & 0.3711 \\
\hline 18 & 0.7035 & 0.3388 & 0.3817 \\
\hline 19 & 0.4434 & 0.7362 & 0.5962 \\
\hline 20 & 0.4335 & 0.5913 & 0.6242 \\
\hline 21 & 0.4241 & 0.6740 & 0.6550 \\
\hline 22 & 0.6352 & 0.4548 & 0.4144 \\
\hline 23 & 0.6152 & 0.3950 & 0.4277 \\
\hline 24 & 0.5964 & 0.4303 & 0.4419 \\
\hline 25 & 1.0000 & 0.3749 & 0.3333 \\
\hline 26 & 0.9513 & 0.3333 & 0.3419 \\
\hline 27 & 0.9071 & 0.3581 & 0.3510 \\
\hline
\end{tabular}

Table 8. Overall grey relational grade

\begin{tabular}{|c|c|}
\hline Ex. No. & Overall grey relational grade \\
\hline 1 & 0.6403 \\
\hline 2 & 0.6991 \\
\hline 3 & 0.7778 \\
\hline 4 & 0.4839 \\
\hline 5 & 0.5055 \\
\hline 6 & 0.5320 \\
\hline 7 & 0.4431 \\
\hline 8 & 0.4509 \\
\hline 9 & 0.4609 \\
\hline
\end{tabular}




\begin{tabular}{|c|c|}
\hline Ex. No. & Overall grey relational grade \\
\hline 10 & 0.5794 \\
\hline 11 & 0.6244 \\
\hline 12 & 0.5845 \\
\hline 13 & 0.4984 \\
\hline 14 & 0.5201 \\
\hline 15 & 0.4934 \\
\hline 16 & 0.4910 \\
\hline 17 & 0.4943 \\
\hline 18 & 0.4747 \\
\hline 19 & 0.5919 \\
\hline 20 & 0.5497 \\
\hline 21 & 0.5844 \\
\hline 22 & 0.5015 \\
\hline 23 & 0.4793 \\
\hline 24 & 0.4895 \\
\hline 25 & 0.5694 \\
\hline 26 & 0.5422 \\
\hline 27 & 0.5387 \\
\hline
\end{tabular}

Table 9. Table for mean of the overall grey relational grade

\begin{tabular}{|c|c|c|c|c|c|c|}
\hline Level & $X_{1}$ & $X_{2}$ & $X_{3}$ & $X_{4}$ & $X_{5}$ & $X_{6}$ \\
\hline 1 & 0.5548 & 0.6257 & 0.5608 & 0.5866 & 0.5332 & 0.5212 \\
\hline 2 & 0.5289 & 0.5004 & 0.5511 & 0.5230 & 0.5406 & 0.5374 \\
\hline 3 & 0.5385 & 0.4961 & 0.5103 & 0.5126 & 0.5484 & 0.5636 \\
\hline Delta & 0.0259 & 0.1296 & 0.0505 & 0.0740 & 0.0152 & 0.0424 \\
\hline Rank & 5 & 1 & 3 & 2 & 6 & 4 \\
\hline
\end{tabular}

Within selected experimental domain the most significant factor becomes pulse duration. Next to pulse duration wire speed, pulse frequency dielectric flow rate, discharge current and wire tension are the parameters in order to influence on responses.

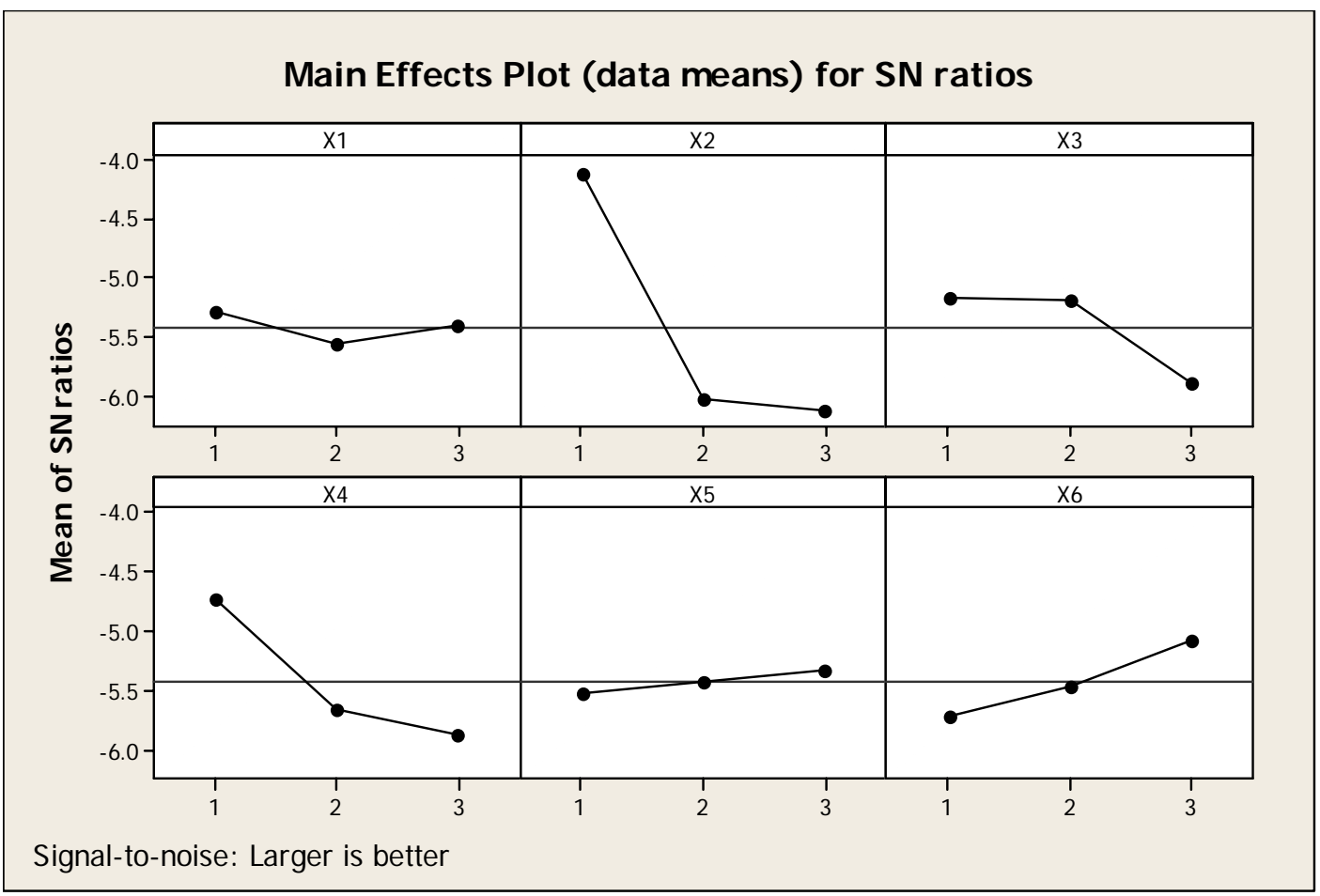

Figure 3. Evaluation of optimal parameter setting 
Table 10. Results of the confirmation experiment for MRR

\begin{tabular}{|l|c|c|}
\hline \multirow{2}{*}{ Level } & \multicolumn{2}{|c|}{ Optimal machining parameter } \\
\cline { 2 - 3 } & $X_{1}(1) X_{2}(1) X_{3}(1) X_{4}(1) X_{5}(3) X_{6}(3)$ & $X_{1}(1) X_{2}(1) X_{3}(1) X_{4}(1) X_{5}(3) X_{6}(3)$ \\
\hline $\begin{array}{l}\text { S/N ratio for } \\
\text { overall grey relational grade }\end{array}$ & -2.62050 & -2.5900 \\
\hline
\end{tabular}

\section{Conclusions}

In the foregoing reporting, an attempt has been made to establish mathematical models to highlight parametric influence on three selected process responses: material removal rate, surface roughness value and width of cut. Response Surface Method has been found efficient for prediction of process responses for various combinations of factor setting. Apart from modeling and simulation, application of grey based Taguchi technique has been utilized to evaluate optimal parameter combination to achieve maximum MRR, minimum roughness value and minimum width of cut; with selected experimental domain. This method is very reliable for solving multi-objective optimization problem; for continuous quality development of the process/product. In the foregoing research it has been assumed that all response features are uncorrelated i.e. they are independent to each other. The response correlation if it exists may be considered in future research.

\section{Appendix}

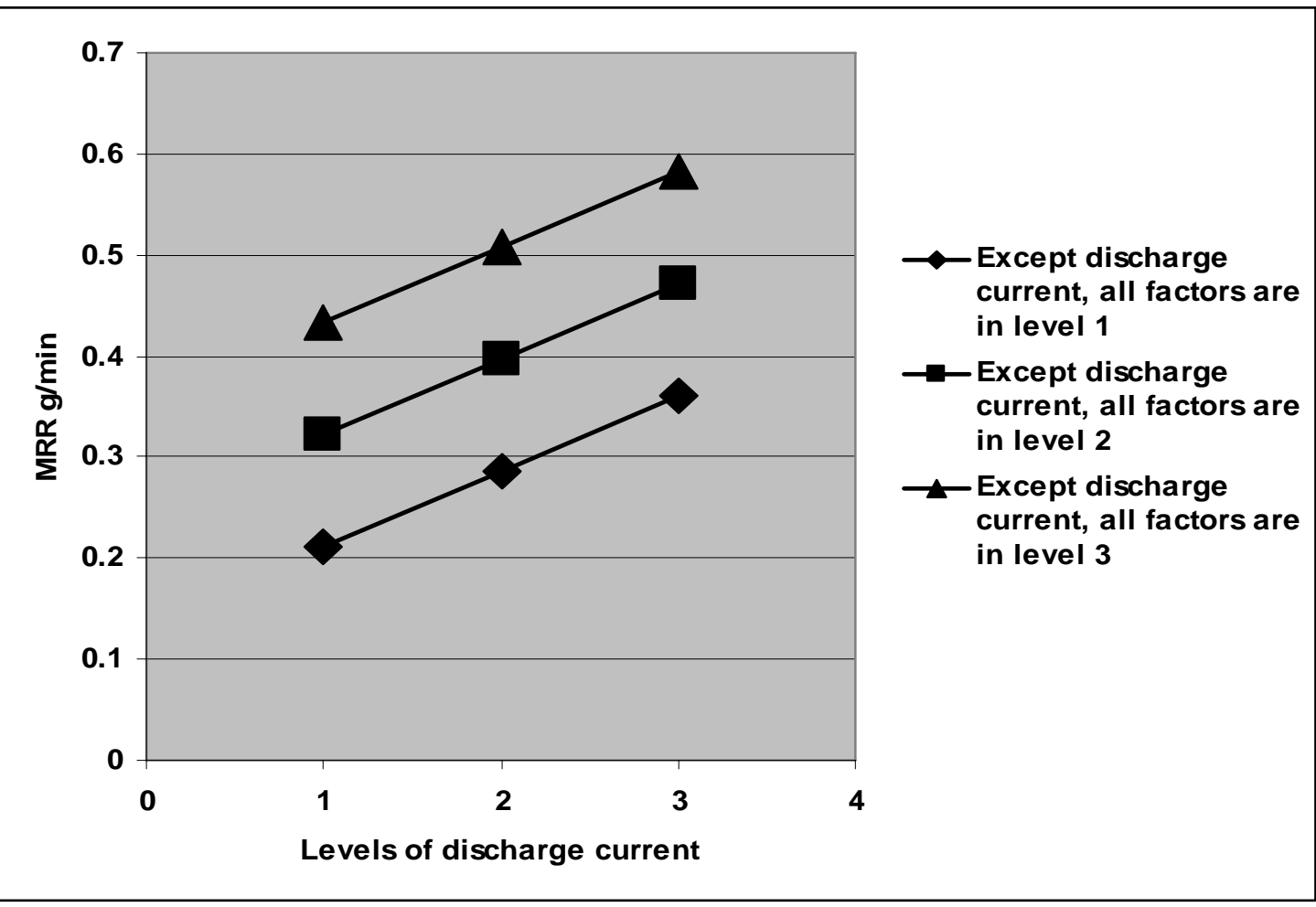

Figure a. Effect of discharge current on MRR 


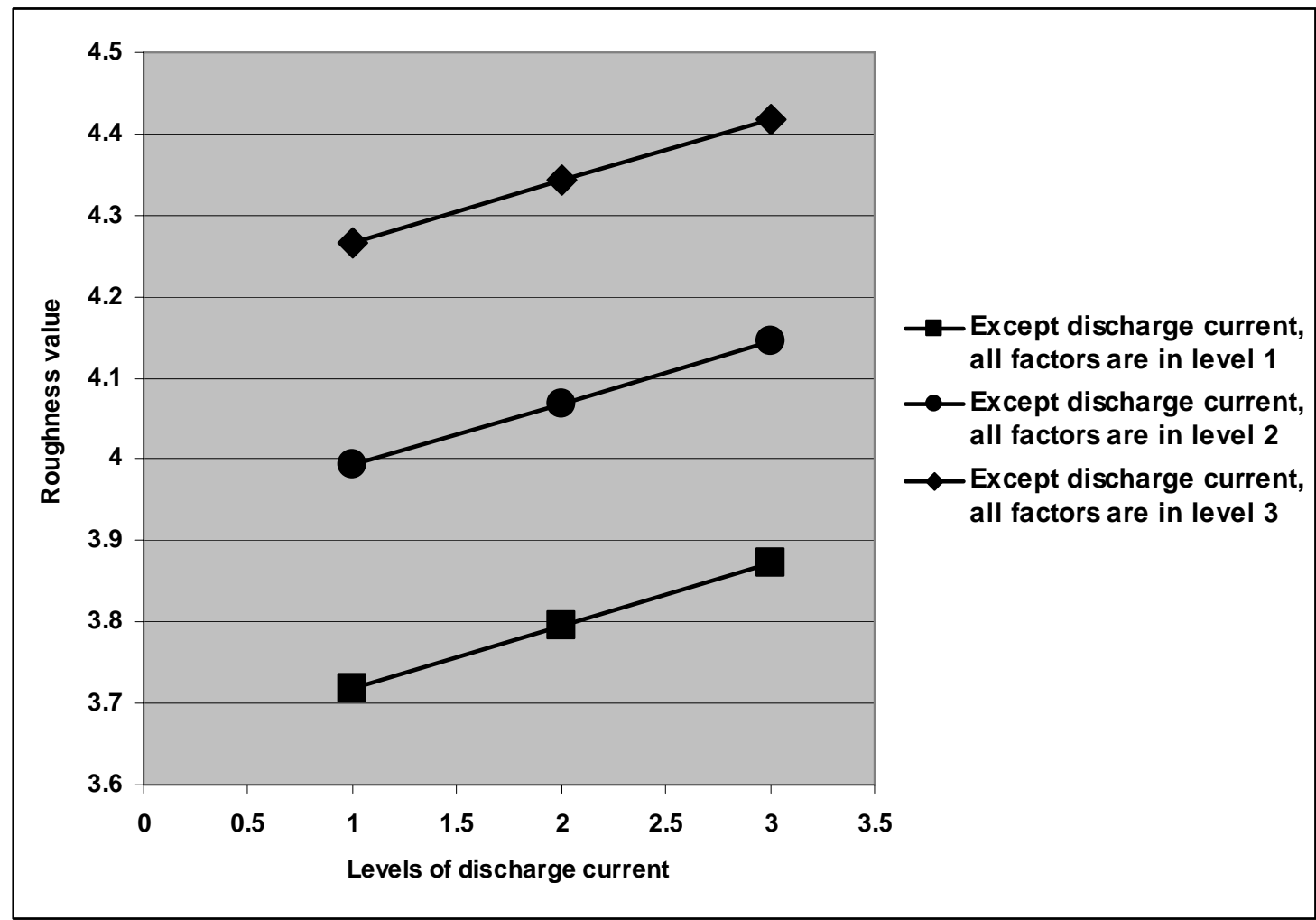

Figure b. Effect of discharge current on roughness value

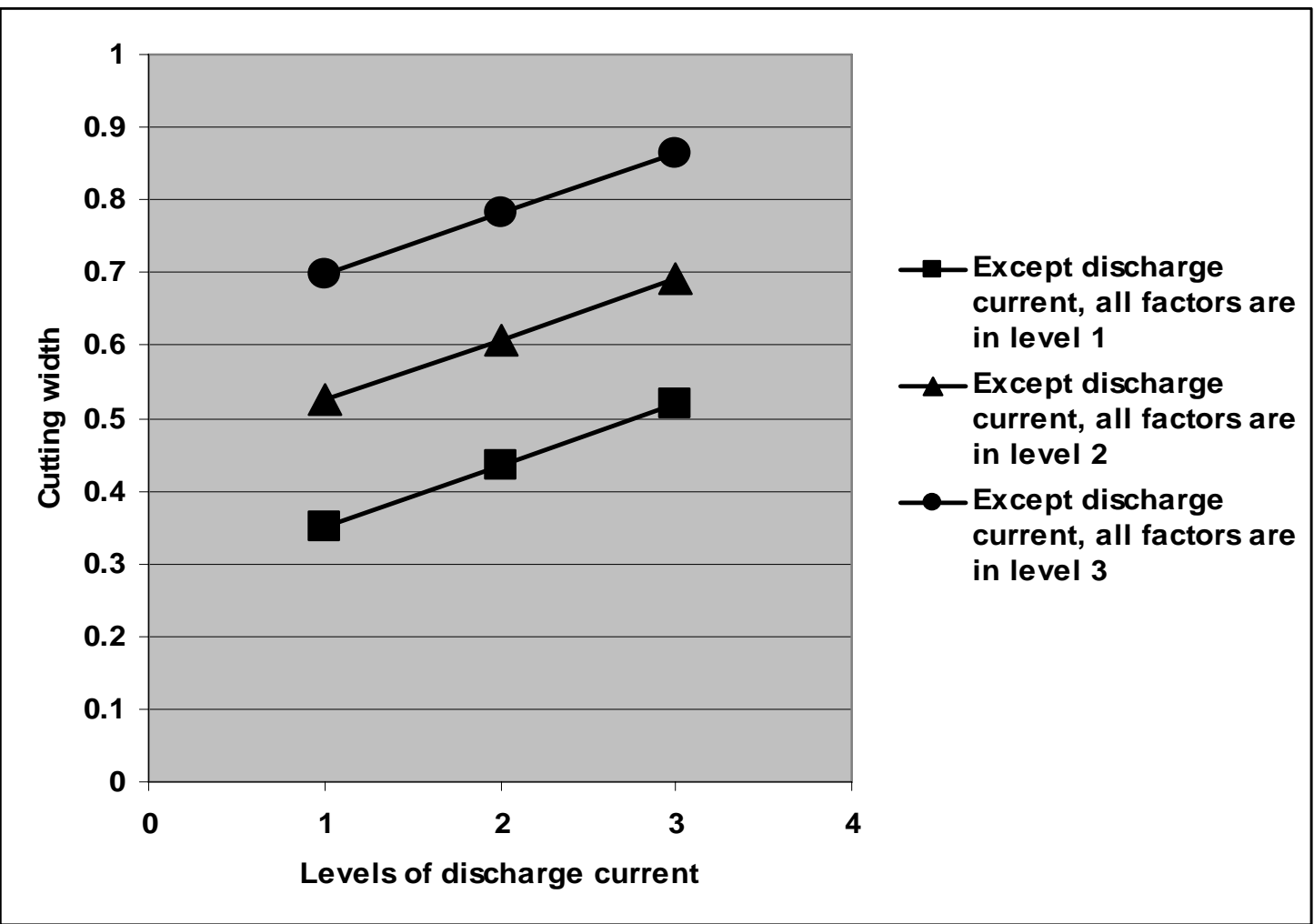

Figure c. Effect of discharge current on cutting width 


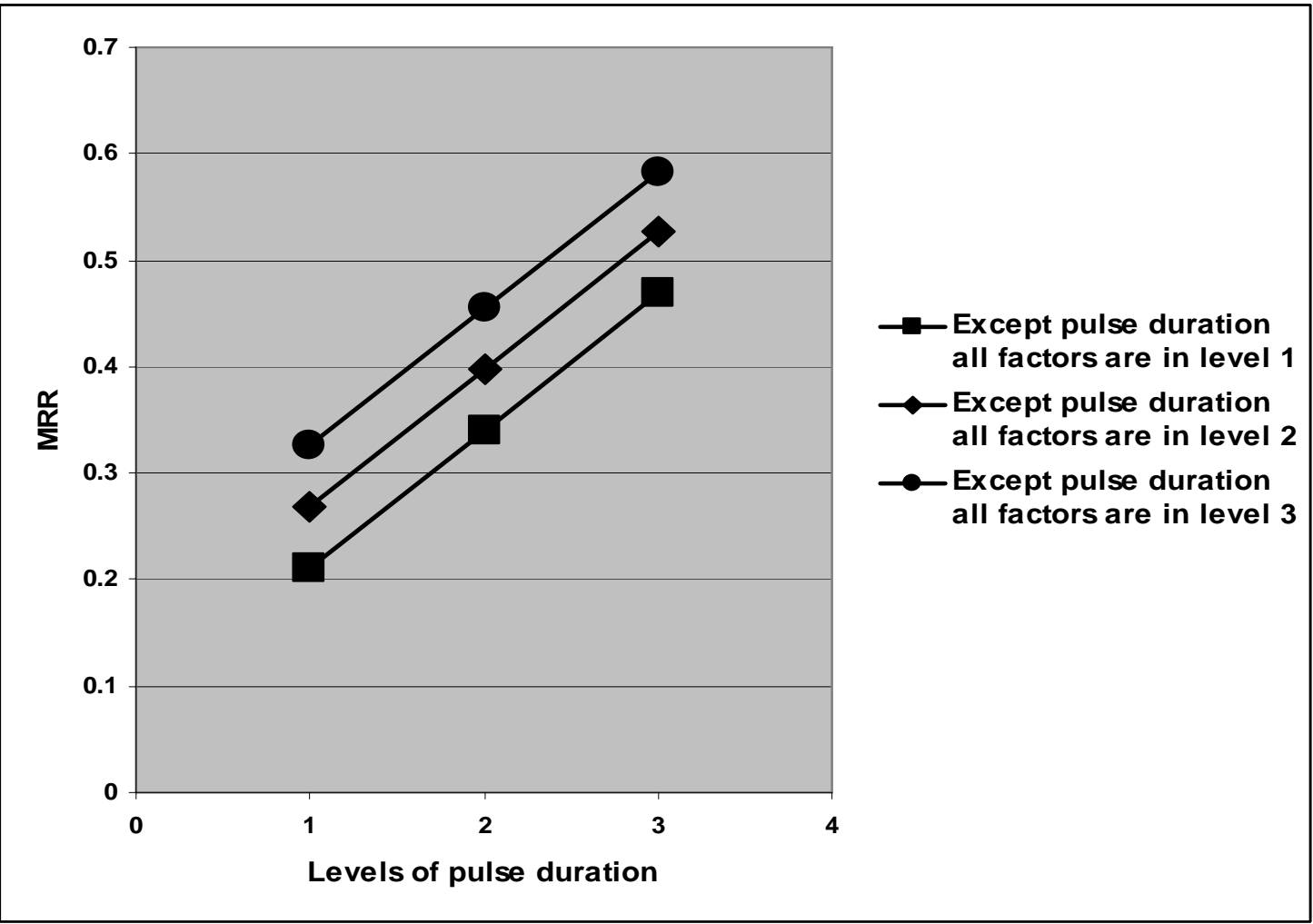

Figure d. Effect of pulse duration on MRR

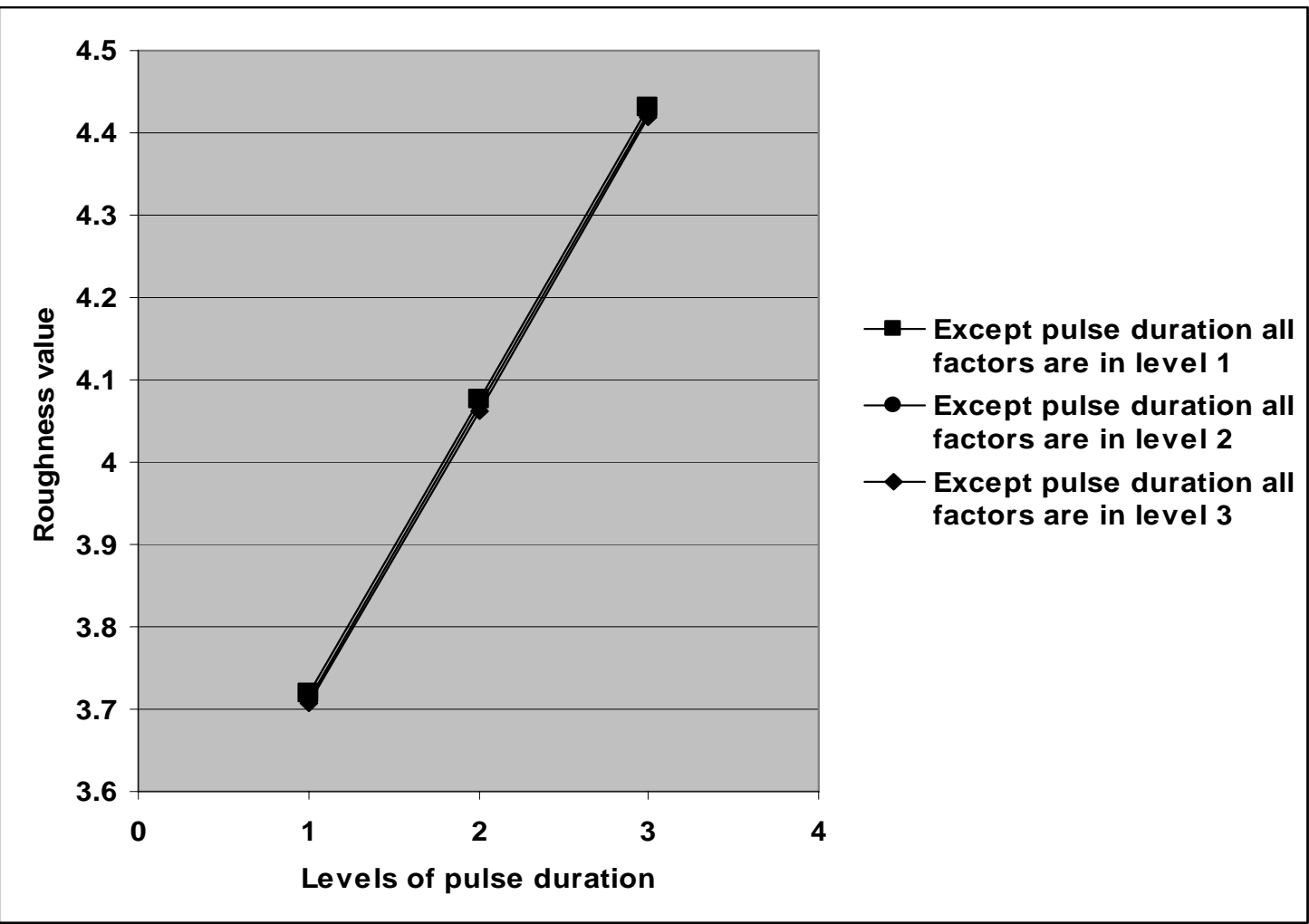

Figure e. Effect of pulse duration on roughness value 


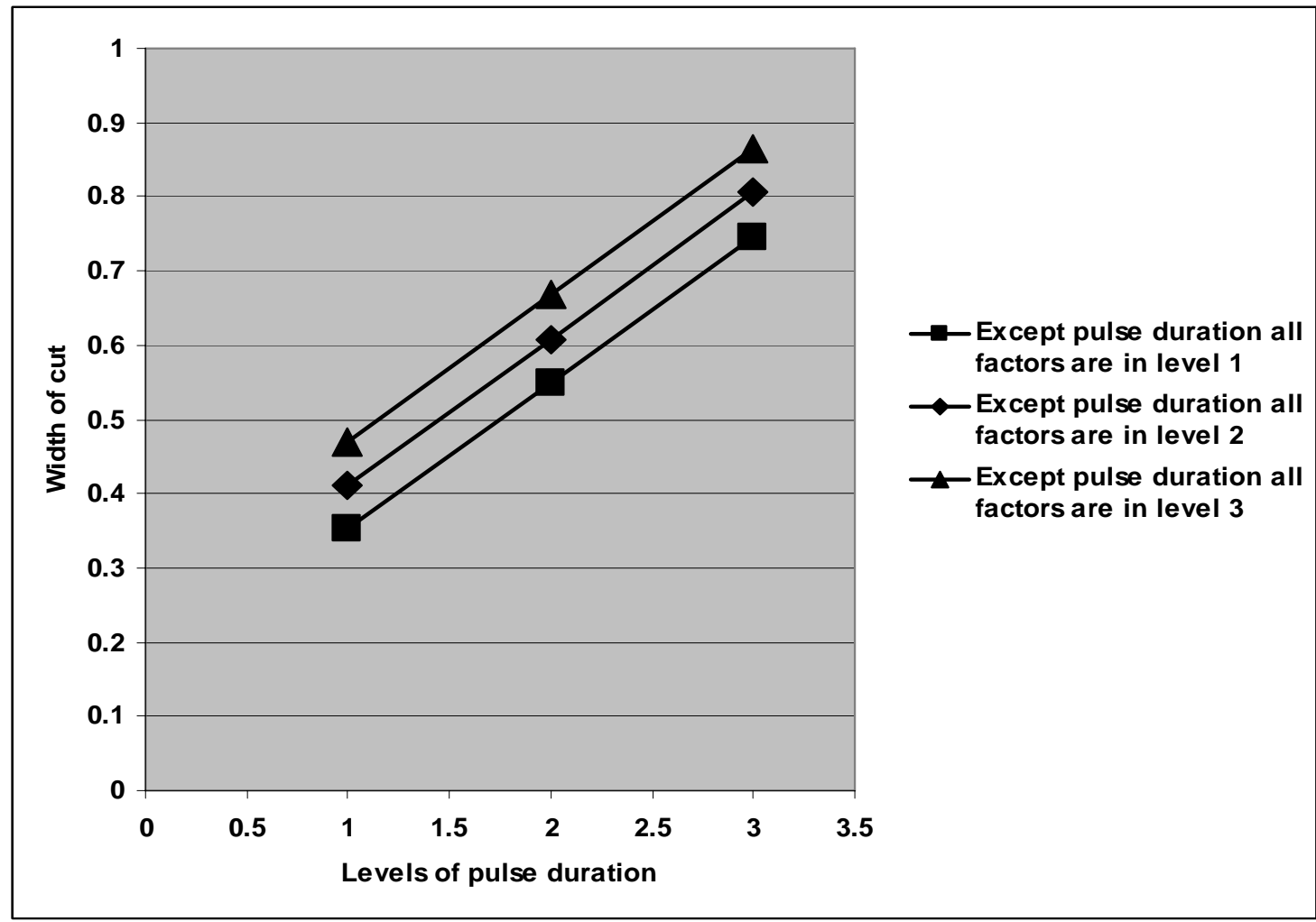

Figure f. Effect of pulse duration on width of cut

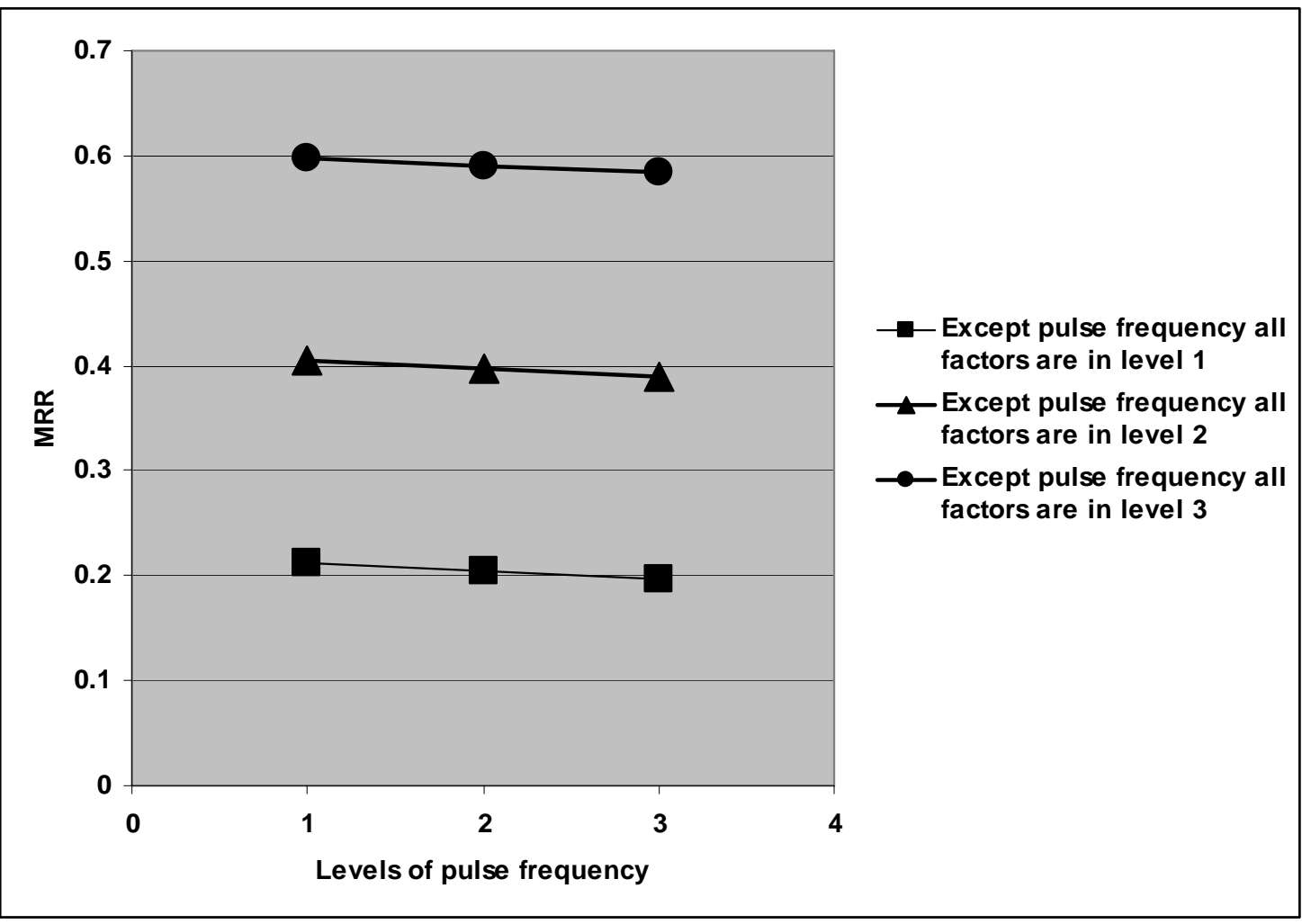

Figure g. Effect of pulse duration on MRR 


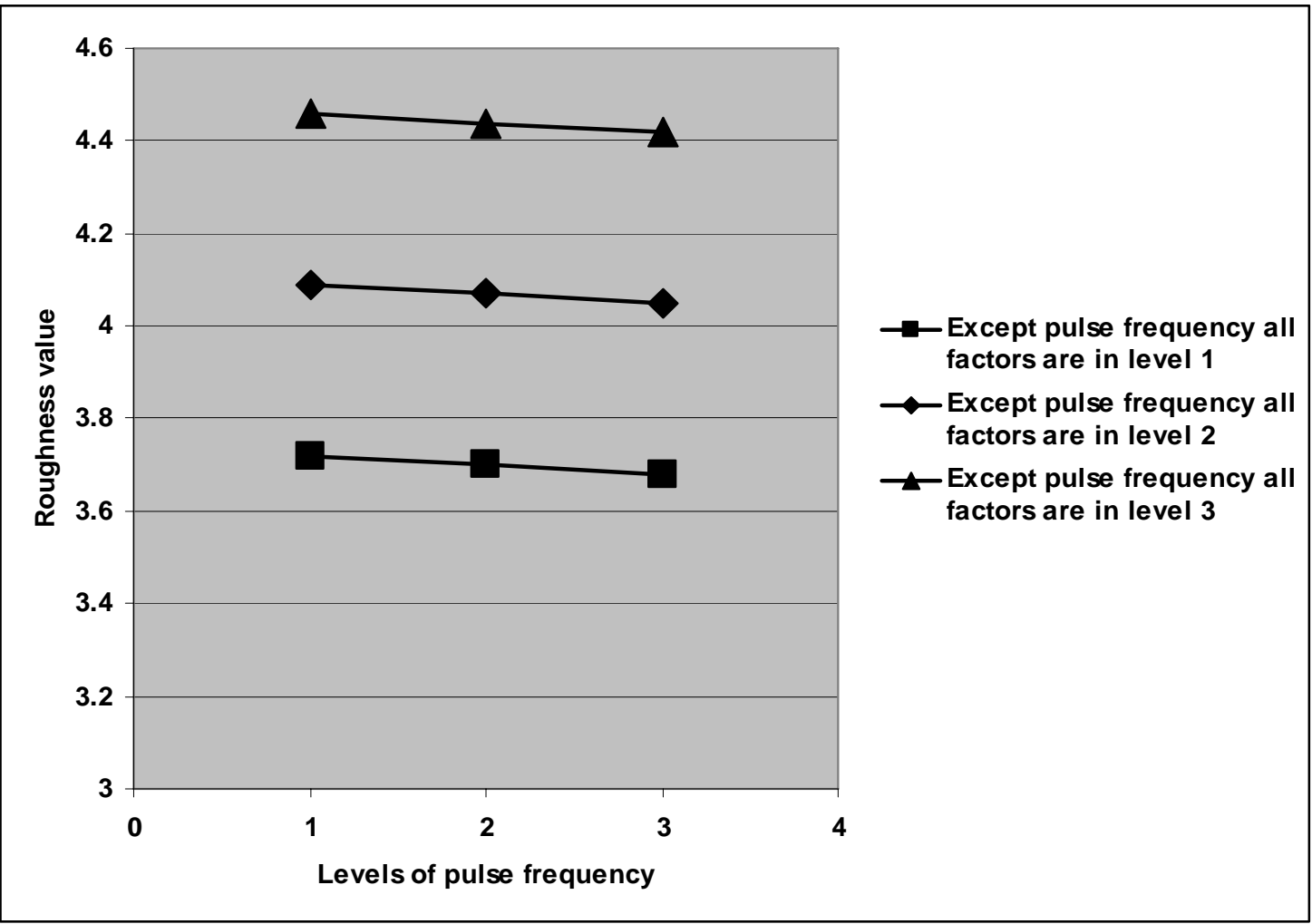

Figure h. Effect of pulse duration on roughness value

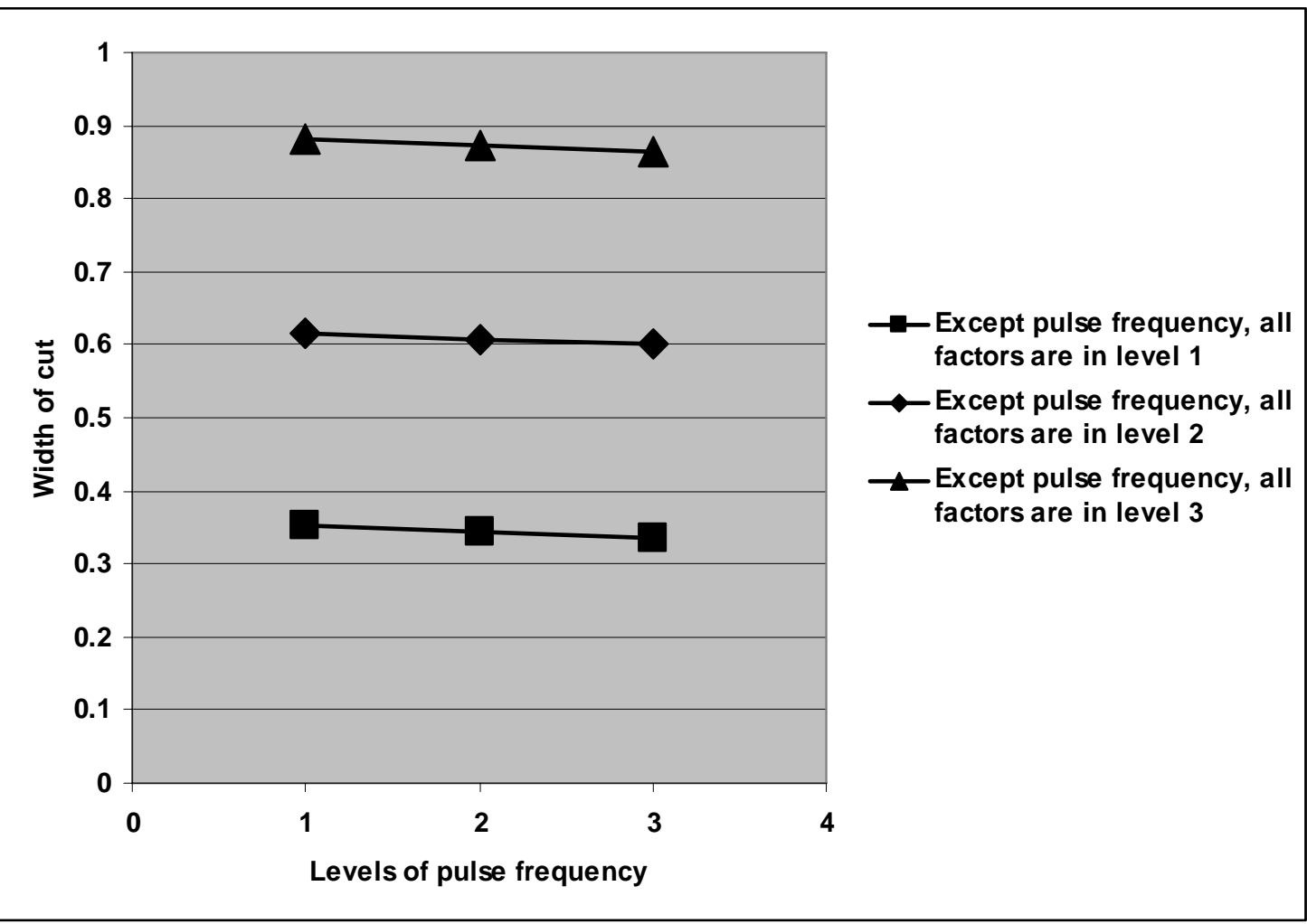

Figure i. Effect of pulse duration on width of cut 


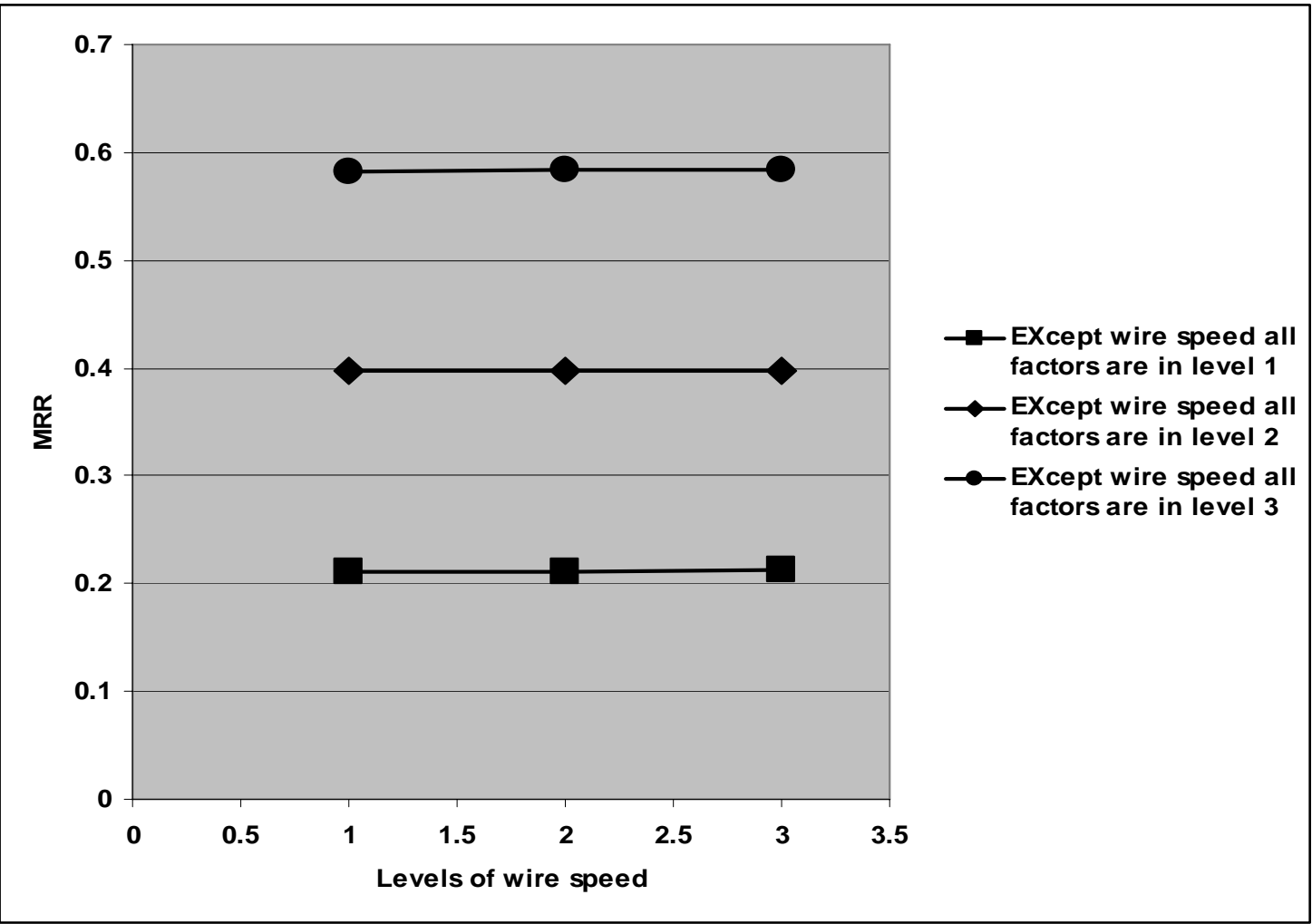

Figure j. Effect of wire speed on MRR

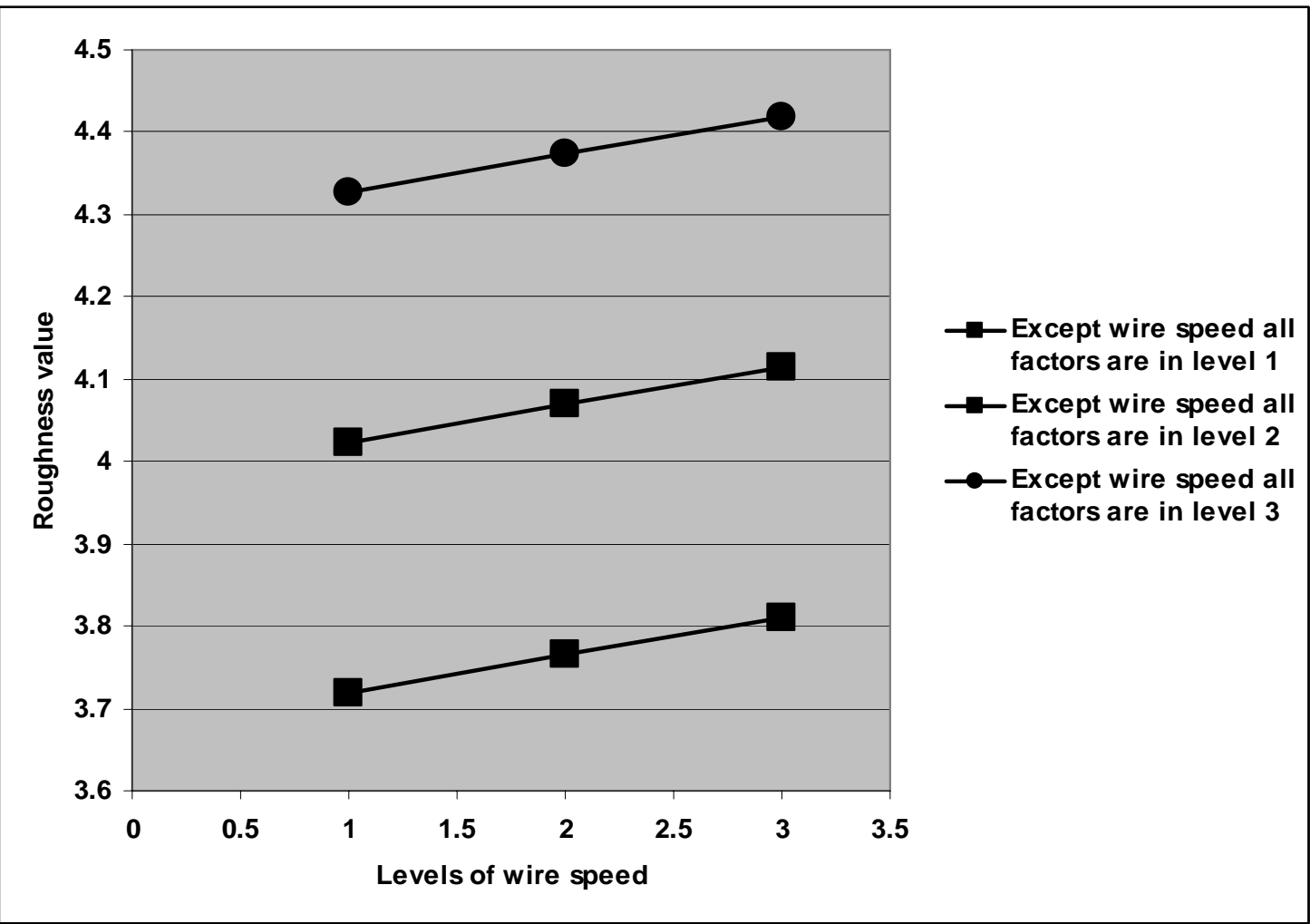

Figure k. Effect of wire speed on roughness value 


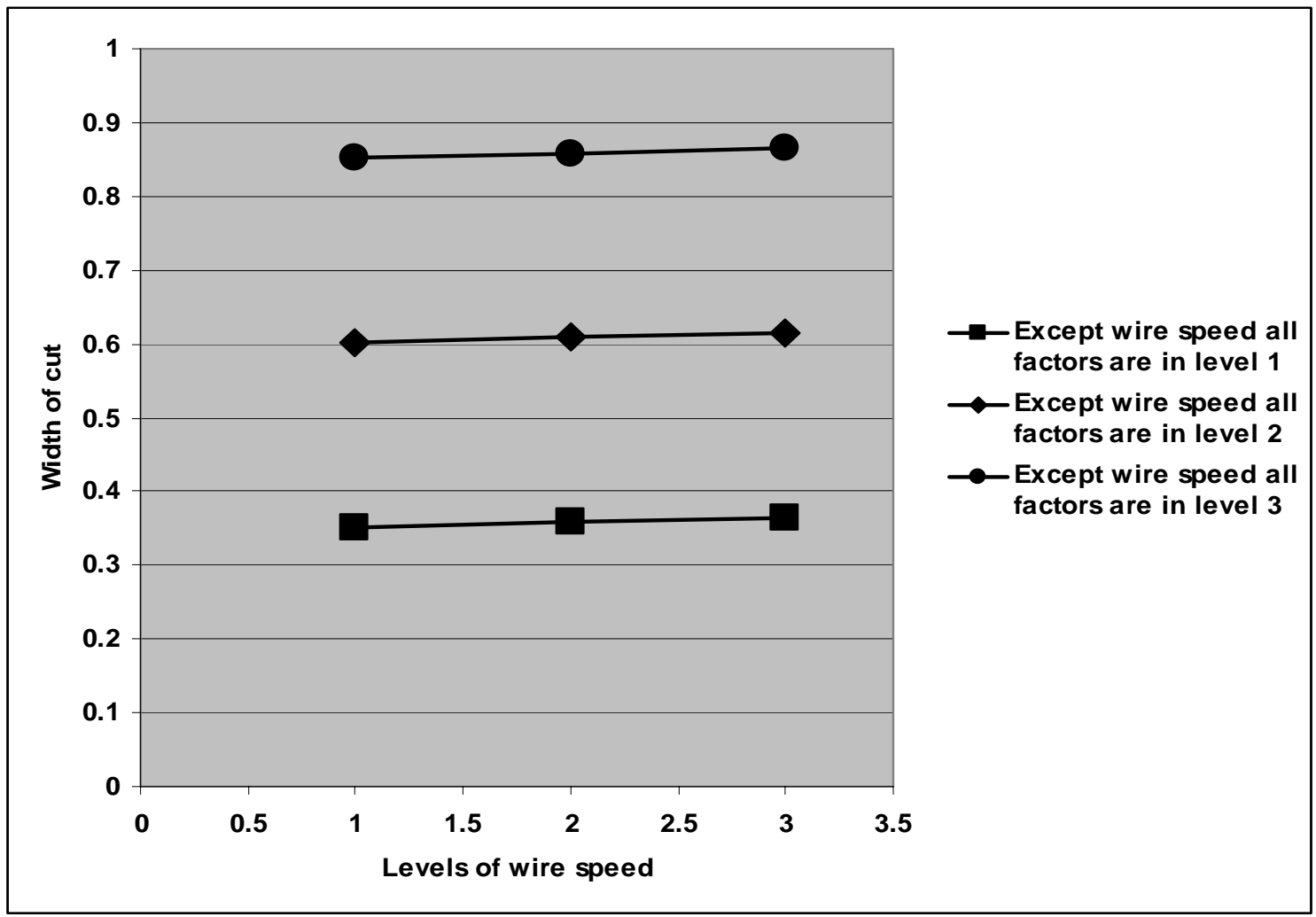

Figure l. Effect of wire speed on width of cut

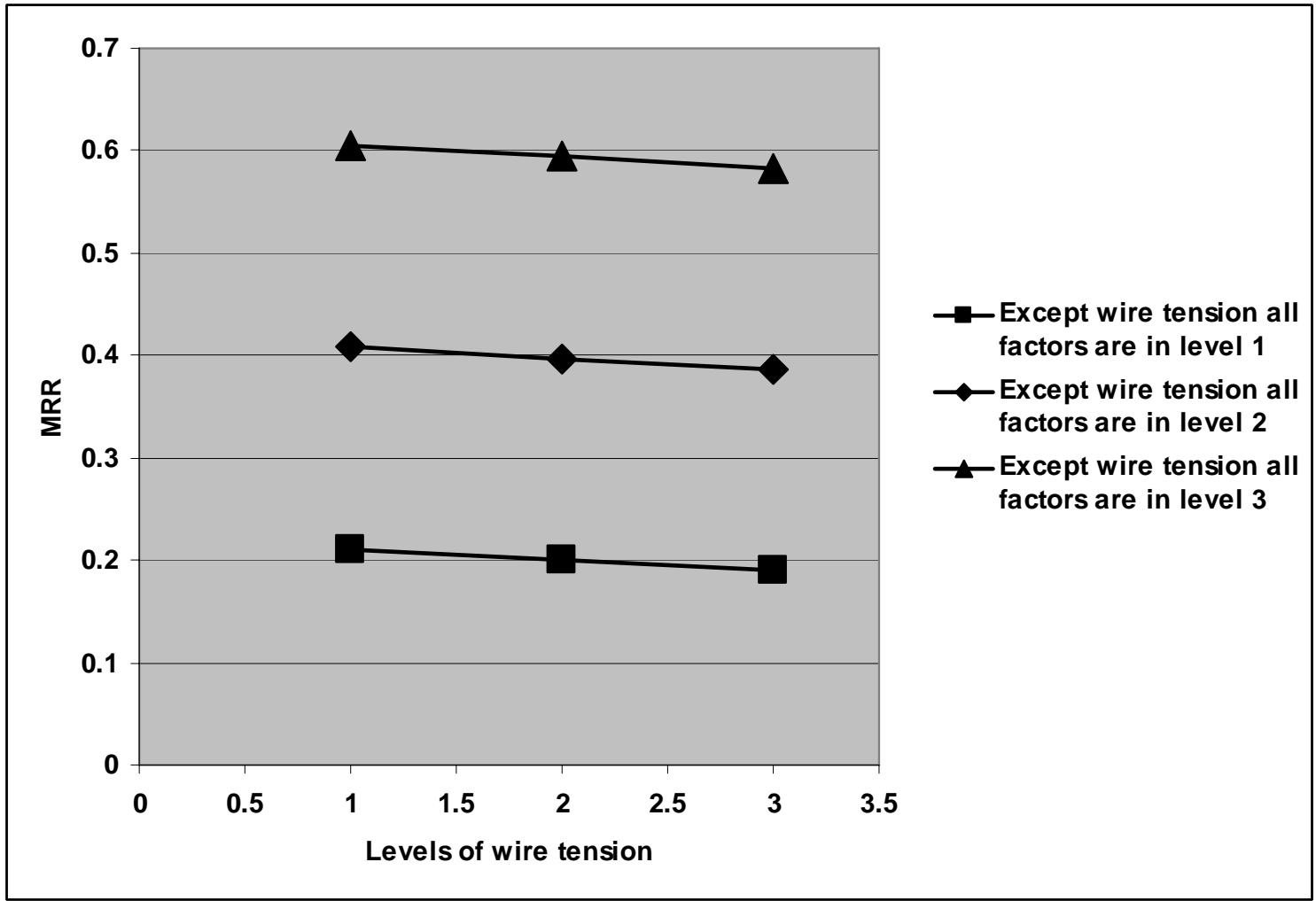

Figure $\mathbf{m}$. Effect of wire tension on MRR 


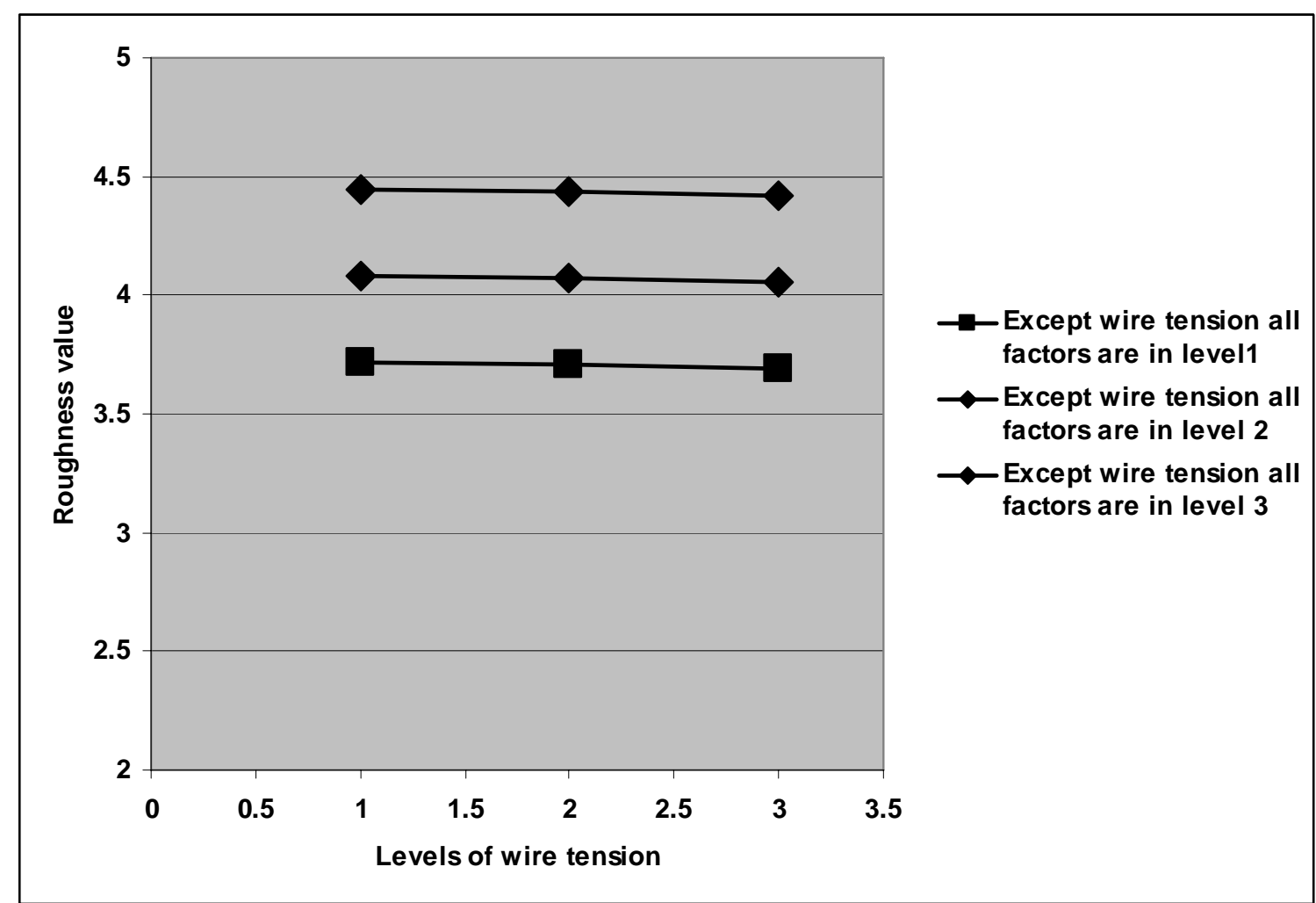

Figure n. Effect of wire tension on roughness value

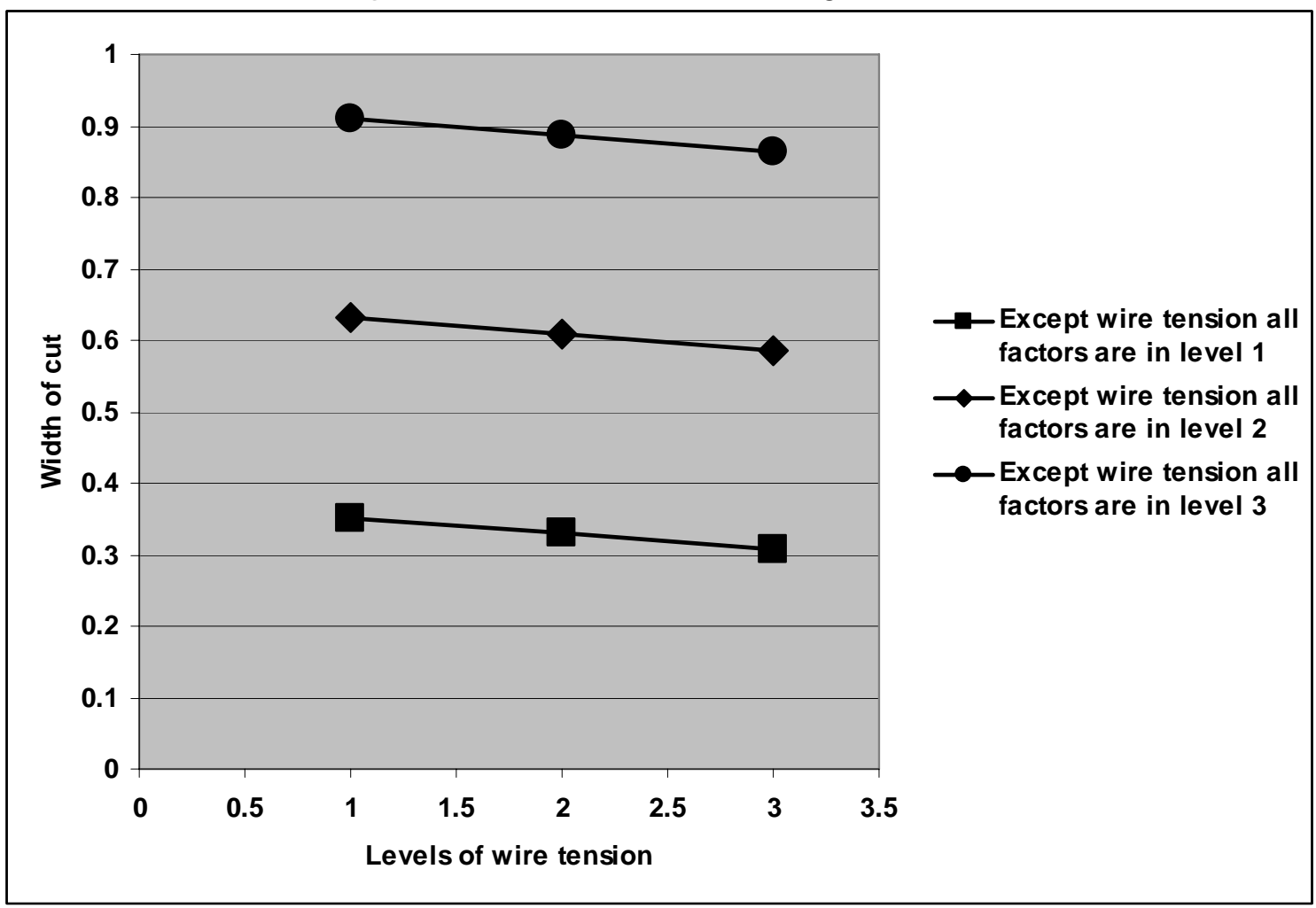

Figure o. Effect of wire tension on width of cut 


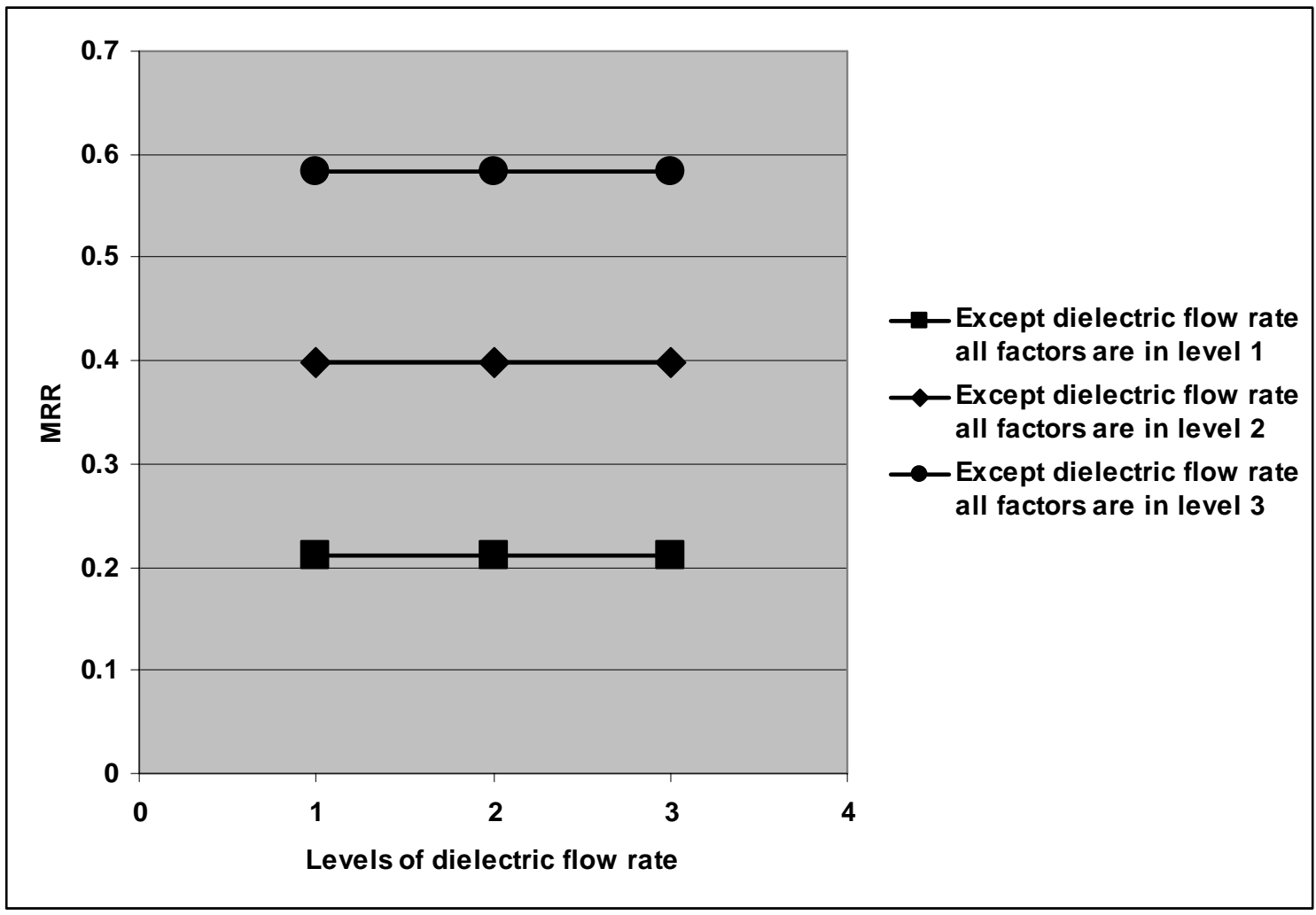

Figure p. Effect of dielectric flow rate on MRR

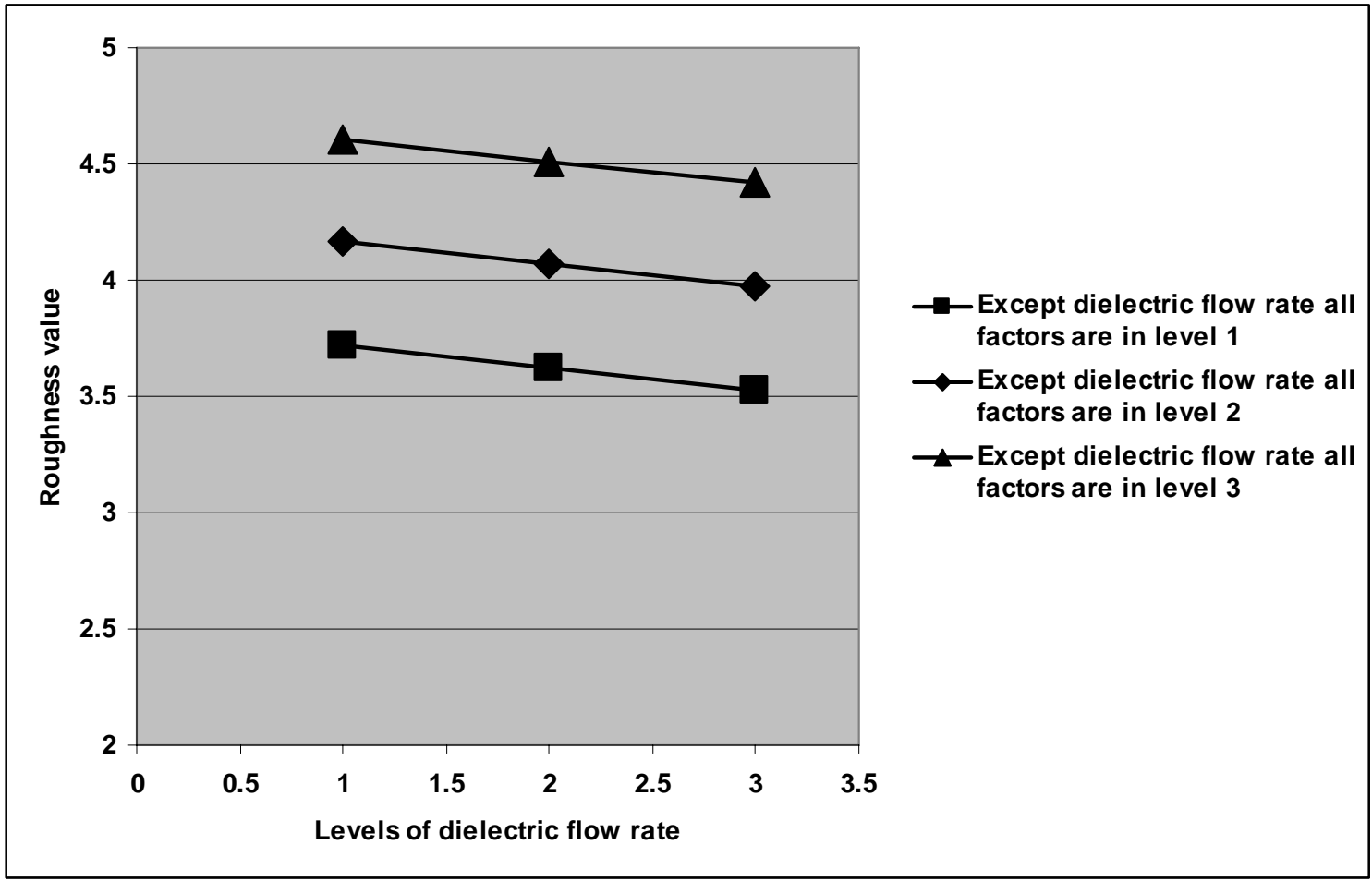

Figure q. Effect of dielectric flow rate on roughness value 


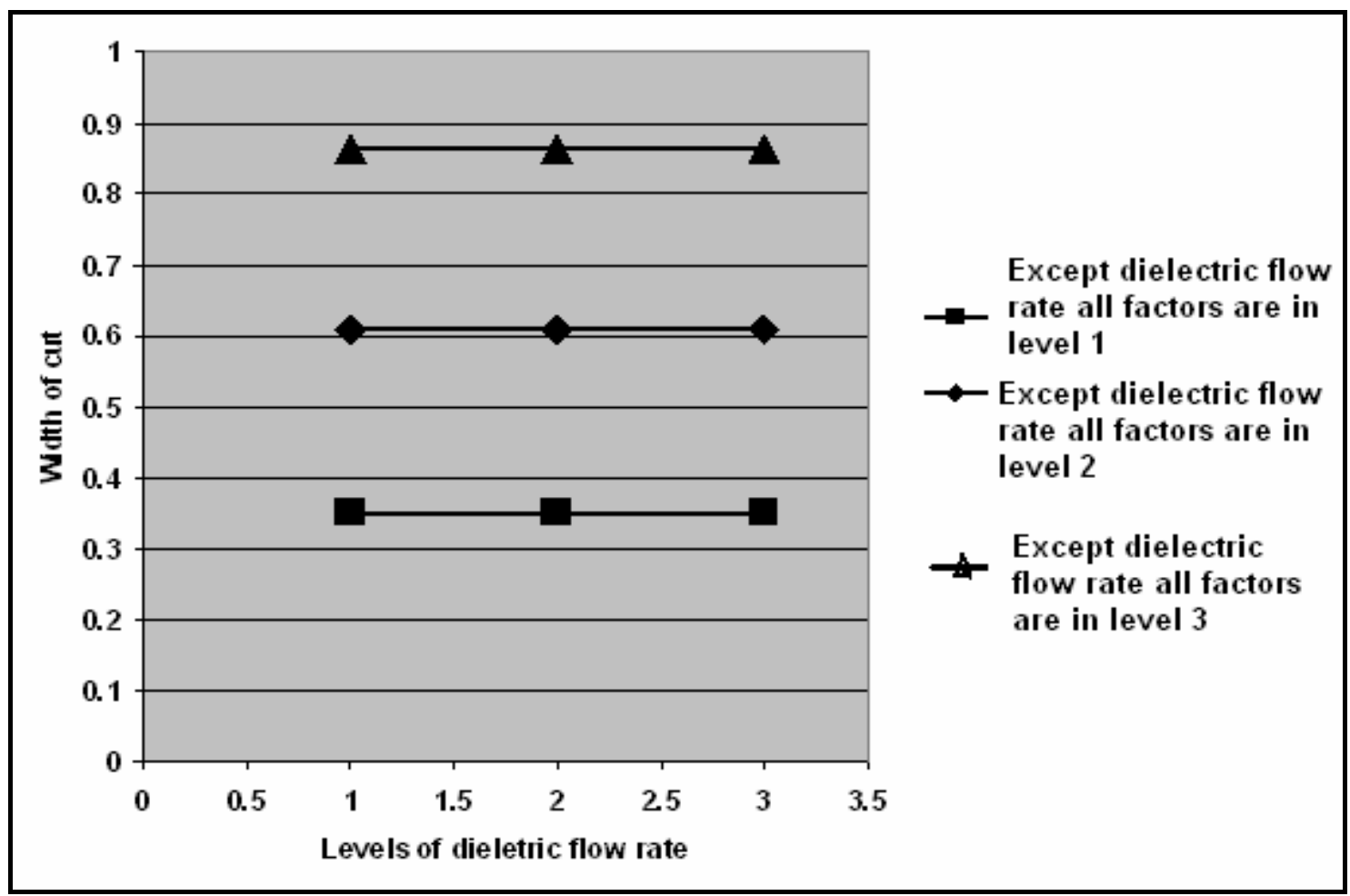

Figure r. Effect of dielectric flow rate on width of cut

Table 11. Effect of process parameters

\begin{tabular}{|c|c|c|}
\hline Response & Parameter & Effect \\
\hline MRR & \multirow{3}{*}{ Discharge Current } & Positive \\
\hline Roughness value & & Positive \\
\hline Width of cut & & Positive \\
\hline MRR & \multirow{3}{*}{ Pulse Duration } & Positive \\
\hline Roughness value & & Positive \\
\hline Width of cut & & Positive \\
\hline MRR & \multirow{3}{*}{ Pulse Frequency } & Negative \\
\hline Roughness value & & Negative \\
\hline Width of cut & & Negative \\
\hline MRR & \multirow{3}{*}{ Wire Speed } & Positive \\
\hline Roughness value & & Positive \\
\hline Width of cut & & Positive \\
\hline MRR & \multirow{3}{*}{ Wire Tension } & Negative \\
\hline Roughness value & & Negative \\
\hline Width of cut & & Negative \\
\hline MRR & \multirow{3}{*}{ Dielectric Flow Rate } & $\begin{array}{l}\text { No specific trend is predicted in } \\
\text { selected domain of experiment }\end{array}$ \\
\hline Roughness value & & Negative \\
\hline Width of cut & & $\begin{array}{l}\text { No specific trend is predicted in selected } \\
\text { domain of experiment }\end{array}$ \\
\hline
\end{tabular}

N.B. Positive effect: With increase in parameter, response increases

Negative effect: With increase in parameter, response decreases

\section{Acknowledgement}

The authors express sincere thanks to the anonymous reviewers whose suggestions made the paper a good contributor. 


\section{References}

Datta, S., Bandyopadhyay, A., Pal, P.K., Nandi, G. and Roy, S.C., 2006. Parametric optimization to achieve maximum depth of penetration in submerged arc double pass butt welding by using Taguchi approach, Proceedings of First International \& $22^{\text {nd }}$ All India Manufacturing Technology Design \& Research Conference (22 ${ }^{\text {nd }}$ AIMTDR), pp. 563-568, held during $21^{\text {st }}-23^{\text {rd }}$ December, IIT Roorkee.

Datta, S., Bandyopadhyay, A. and Pal, P.K., 2008. Grey based Taguchi method for optimization of bead geometry in submerged arc bead-on-plate welding. International Journal of Advanced Manufacturing Technology, Vol. 39, pp. 1136-1143.

Huang, J.T., Liao, Y.S. and Hsue, W.J., 1999. Determination of finish-cutting operation number and machining parameters setting in wire electrical discharge machining. Journal of Materials Processing Technology, Vol. 87, pp. 69-81.

Glen Stuart Peace (1993) Taguchi methods: a hands on approach. Addison-Wesley, New York.

Lok, Y.K. and Lee, T.C., 1997. Processing of advanced ceramics using the wire-cut EDM process. Journal of Materials Processing Technology, Vol. 63, No 1-3, pp. 839-843.

Mahapatra, S.S. and Patnaik, A., 2007. Optimization of wire electrical discharge machining (WEDM) process parameters using Taguchi method, International Journal of Advanced Manufacturing Technology, Vol. 34, pp. 911-925.

Madhav S. Phadke (1989) Quality Engineering using Robust Design. Prentice Hall, Eaglewood Cliffs, New Jersey.

Moshat, S., Datta, S., Bandyopadhyay, A. and Pal, P.K., 2010. Optimization of CNC end milling process parameters using PCA based Taguchi method. International Journal of Engineering, Science and Technology, Vol. 2, No 1, pp. 92-102.

Moshat, S., Datta, S., Bandyopadhyay, A. and Pal, P.K., 2010. Parametric optimization of CNC end milling using entropy measurement technique combined with grey-Taguchi method. International Journal of Engineering, Science and Technology, Vol. 2, No 2, pp. 1-12.

Montgomery, D. C., Peck, E. A. and Vining, G. Geoffrey, Introduction to Linear Regression Analysis, Third Edition, Jhon Wiley \& Sons, INC.

Rajurkar, K.P. and Wang, W.M., 1993. Thermal modeling and on-line monitoring of wire-EDM. Journal of Materials Processing Technology, Vol. 38, No 1-2, pp. 417-430.

Rozenek, M., Kozak, J., DabroVwki, L. and LubkoVwki, K., 2001. Electrical discharge machining characteristics of metal matrix composites. Journal of Materials Processing Technology, Vol. 109, pp. 367-370.

Sho, H., Orimo, T. and Fukui, M., 1989. The effect of electrode materials on the characteristics of machinability of wire electro discharge machines, Proceedings of the international symposium for electro machining, (ISEM-9) Nagoya: 219-222.

Scott, D., Boyina, S. and Rajurkar, K.P., 1991. Analysis and optimization of parameter combination in wire electrical discharge machining. International Journal of Production Research, Vol.29, No 11, pp. 2189- 2207.

Trezise, K.E, 1982. A physicist's view of wire EDM, Proceedings of the International Conference on Machine Tool Design and Research. Vol. 23, pp. 413-419.

Tarng, Y.S., Ma, S.C. and Chung, L.K. 1995. Determination of optimal cutting parameters in wire electrical discharge machining. International Journal of Machine Tools and Manufacture, Vol. 35, No 129, pp.1693-170.

Tosun, N. and Cogun, C., 2003. An investigation on wire wears in WEDM. Journal of Materials Processing Technology, Vol. 134, No 3, pp. 273-278.

Tosun, N., Cogun, C. and Pihtili, H., 2003. The effect of cutting parameters on wire crater sizes in wire EDM, International Journal of Advanced Manufacturing Technology, Vol. 21, pp. 857-865.

\section{Biographical notes}

Dr. Saurav Datta received B. E. (Mechanical) and Ph.D. (Engineering) from Jadavpur University Kolkata, India in 2003 and 2008, respectively. He is an Assistant Professor in the Department of Mechanical Engineering, National Institute of Technology Rourkela, India. He has more than five years of experience in teaching and research. His research interests include Welding, Modeling-Simulation and Optimization of Production Processes and Multi-Criteria Decision-Making (MCDM) problems. He is a Life Associate Member of Indian Institute of Welding IIW (India). He has published more than twenty papers in referred international journals. He has also published more than fifty research articles in proceedings of various national and international conferences.

Prof. Siba Sankar Mahapatra is a Professor in the Department of Mechanical Engineering, National Institute of Technology Rourkela, India. He has more than 20 years of experience in teaching and research. His current area of research includes Multi-criteria Decision-Making, Quality Engineering, Assembly Line Balancing, Group Technology, Neural Networks, and Non-traditional Optimization and Simulation. He has published more than fifty papers in referred international journals. He has also presented more than one hundred research articles in national and international conferences. He has written few books related to his research work. He is currently dealing with few projects sponsored by government of India.

Received June 2010

Accepted July 2010

Final acceptance in revised form August 2010 